\title{
The Role of Retardation, Attachment and Detachment Processes during Microbial Coal-Bed Methane Production after Organic Amendment
}

\author{
Simon Emmert ${ }^{1, *,+}$, Katherine Davis ${ }^{2}\left[\right.$, Robin Gerlach ${ }^{2,3}$ and Holger Class $^{1}{ }^{1(D)}$ \\ 1 Institute for Modelling Hydraulic and Environmental Systems, University of Stuttgart, Pfaffenwaldring 61, \\ 70569 Stuttgart, Germany; holger.class@iws.uni-stuttgart.de \\ 2 Center for Biofilm Engineering, Montana State University, 366 Barnhard Hall, Bozeman, MT 59717, USA; \\ katherine.davis@montana.edu (K.D.); robin_g@montana.edu (R.G.) \\ 3 Department of Chemical and Biological Engineering, Montana State University, 306 Cobleigh Hall, Bozeman, \\ MT 59717, USA \\ * Correspondence: simon.emmert@iws.uni-stuttgart.de; Tel.: +49-711-685-67015 \\ + Current address: Department of Hydromechanics and Modelling of Hydrosystems, Institute for Modelling \\ Hydraulic and Environmental Systems, University of Stuttgart, Pfaffenwaldring 61, \\ 70569 Stuttgart, Germany.
}

Received: 8 September 2020; Accepted: 20 October 2020; Published: 27 October 2020

\begin{abstract}
Microbially enhanced coal-bed methane could allow for a more sustainable method of harvesting methane from un-mineable coaldbeds. The model presented here is based on a previously validated batch model; however, this model system is based on upflow reactor columns compared to previous experiments and now includes flow, transport and reactions of amendment as well as intermediate products. The model implements filtration and retardation effects, biofilm decay, and attachment and detachment processes of microbial cells due to shear stress. The model provides additional insights into processes that cannot be easily observed in experiments. This study improves the understanding of complex and strongly interacting processes involved in microbially enhanced coal-bed methane production and provides a powerful tool able to model the entire process of enhancing methane production and transport during microbial stimulation.
\end{abstract}

Keywords: reactive transport modelling; microbially enhanced coal-bed methane production; biofilm growth and decay; amendment retardation

\section{Introduction}

With a rising demand for energy [1,2], innovative, sustainable, and renewable processes for energy production are needed. One contribution to more sustainable utilization of existing resources could be microbially enhanced coal-bed methane (MECBM) production.

MECBM production is a process to enhance methane production from un-mineable coal beds by utilizing microbes. Experimental investigations demonstrate the potential of the technology [3-6]. Barnhart et al. [4] and Davis et al. [5,7] present successive experimental batch investigations using coal and microbial consortia from the Powder River Basin. The extension to the column-scale is presented in the study of Davis et al. [8], using the same crushed coal as for the batch investigations. Instead of crushed coal, Lupton et al. [9] used intact coal cores from already producing coal-bed methane fields and generated comparable methane amounts to batch studies that used crushed coal. Analysis of the microbial community and potential substrate limitations of e.g., archaea in a long-term study are presented by Beckmann et al. [10] and Davis et al. [5]. With many experimental investigations, very few modeling studies have been published [11-14] and modeling is very useful if 
not necessary for the scale-up of MECBM technologies. The studies of Senthamaraikkannan et al. [12] use a simplified enzymatic reaction model and combined it with a transport model to simulate a dual-porosity column [11]. Saurabh and Harpalani [13] approximate the series of reactions involved using a single lumped reaction, while Emmert et al. [14] use a complex food-web to include three different ways of methanogenesis by archaea.

Emmert et al. [14] provide a numerical batch model that includes the fundamental processes of microbial growth and governing reactions involved for bacteria and archaea; this model was developed to be extended to simulate column and field case studies. By focusing on the modeling of upflow column reactors and comparing the simulation results against experimental data [8], this study is taking the next step from Emmert et al. [14]. Davis et al. [8] present a column-scale study, where the same coal and amendment from previous batch studies are used. Since the reactions of the numerical model by Emmert et al. [14] are calibrated and validated with this experimental batch data, only minor adjustments are needed in principle to include flow and transport for this study. The goal is to improve insight into relevant processes involved in MECBM on the column scale. Therefore, the numerical model is set up with different scenarios to test various hypotheses. The scenarios include (i) using the batch reaction kinetics with flow and transport, (ii) using the same model with changed boundary conditions to model inlet clogging, (iii) an extension of the model to capture retardation of the particulate amendment added to the columns, and (iv) cell attachment and detachment processes are investigated. Substantial work has been done in the field of modeling filtration [15-17]; however most studies consider only a single fluid phase with respect to filtration. Therefore, the filtration equations are only used for the aqueous phase and its components. The porous medium (coal) and biofilm as well as possibly suspended microbial cells can interact and add additional complexity to the model. This model can account for the effects of additional decay or transport of microbes through shear stress, induced by the flow in the porous medium. Attachment and detachment of microbes or substrate are implemented as well.

We have learned that kinetics in flow-through systems are affected by transport processes, and therefore often do not match expectations based on batch kinetics, which is in line with previous studies from other fields ([18-20]). Further steps, e.g., modeling simple retardation or varying inlet conditions, result in a qualitatively good match of experimental and numerical results for methane production, but we show in this study that it is important to look also at the process of substrate consumption. Note that we have a complex food web where different types of microbes consume specific substrates, mainly coal and amendment, but also intermediate products [14].

There are different mechanisms that can be implemented in the model to account for and explain experimental observations and to achieve a reasonable match of the model results with the experimental data. We show here that a combination of these mechanisms yields the most plausible results. For example, we consider increased biofilm inactivation and decay as well as the retardation of amendment in the porous column, and we can show that in this case, a combination of cell attachment and detachment with amendment retardation produces the best results. In this study, retardation of amendment leads to a slower and more continuous or homogenized transport of amendment through the column, essentially causing a slower release of amendment for the microbial community. Therefore, retardation in this context is considered to be a phenomenon that can facilitate and enhance the growth of microbes and methane production. With this study, we show the clear advantage of the model in being able to measure the generation of methane inside the column, but also the production of methane leaving the column in total, while at the same time monitoring concentrations of substrates and intermediate products inside the column, which is not easily done in experiments.

The presented model uses approaches from the field of modeling biofilms in aquatic porous media and includes them into the model to study the effects on methane production and the evolution of microbial cells and biofilms in porous media. The strong interactions and interdependencies between solutes, reactions, and biofilms are potentially of interest for many aquatic systems. 


\section{Materials and Methods}

This section has its focus on the description of the numerical model and the relevant processes involved in column-scale MECBM production. The conceptual model as well as the reaction kinetics are defined in Emmert et al. [14]. This model advances the batch model to a fully-coupled reactive transport model. It considers two fluid phases (aqueous and gaseous), multiple components within the fluid phases, as well as six solid phases (coal matrix and five microbial species as a biofilm). The components are transported with the fluid phases and converted by the reactions, which take place "inside" the biofilm. This biofilm is generally attached to the porous matrix and is able to grow and decay. All these processes appear on the pore-scale; however, we treat them in an averaged sense on the scale of a Representative Elementary Volume (REV), as previously discussed in Hommel et al. [21], and apply them using REV-scale parameters and equations that describe the porous medium with its interactions between solid matrix, biofilm, components and fluids. We do not model component transport or flow inside the biofilm but rather keep the biofilms rigid on the porous matrix so that they potentially interact with flow and transport. Porosity and permeability are updated accordingly.

In the following, we first describe the general conservation equations used for all model scenarios. We specify then the changes made to the model for the different scenarios. We assume incompressible, miscible, and non-isothermal flow of the two fluid-phases on the REV scale using Darcy's law. Components can dissolve in the two fluid phases and we solve one mass balance equation for each component in each fluid phase as presented in Helmig et al. [22]. The general reaction kinetics and parameters regarding the reactions are already described in Emmert et al. [14]. The reaction kinetics from Emmert et al. [14] are incorporated in the source term of each component conservation equation.

\subsection{Conservation Equations}

Conservation equations to model the continuity of mass for two fluid phases $\alpha$ and six components $\kappa$ in each phase are described in Equation (1):

$$
\sum_{\alpha}\left[\frac{\partial}{\partial t}\left(\phi \rho_{\mathrm{mol}, \alpha} x_{\alpha}^{\kappa} S_{\alpha}\right)+\nabla \cdot\left(\rho_{\mathrm{mol}, \alpha} x_{\alpha}^{\kappa} \mathbf{v}_{\alpha}\right)-\nabla \cdot\left(\rho_{\mathrm{mol}, \alpha} \mathbf{D}_{\mathrm{pm}, \alpha}^{\kappa} \nabla x_{\alpha}^{\kappa}\right)\right]=q^{\kappa} \quad \alpha \in\{\mathrm{n} ; \mathrm{w}\} .
$$

Here, $t$ is time, $\phi$ is porosity, $\rho_{\mathrm{mol}, \alpha}$ is the molar density, $S_{\alpha}$ is saturation, and $\mathbf{v}_{\alpha}$ is the velocity of phase $\alpha ; x_{\alpha}^{\kappa}$ is the mole fraction of component $\kappa$ in phase $\alpha$ and $\mathbf{D}_{\mathrm{pm}, \alpha}^{\kappa}$ is the diffusion tensor in phase $\alpha$. Sources and sinks due to biogeochemical reactions for component $\kappa$ are captured by $q^{\kappa}$.

The multiphase extension for Darcy's Law in Equation (2) is used to compute the fluids' Darcy velocities as:

$$
\mathbf{v}_{\alpha}=-\frac{k_{r \alpha}}{\mu_{\alpha}} K\left(\nabla p_{\alpha}-\rho_{\alpha} \mathbf{g}\right),
$$

where $k_{r \alpha}, p_{\alpha}$, and $\rho_{\alpha}$ are the relative permeability, pressure and density of phase $\alpha$ respectively; $\mu_{\alpha}$ is the respective dynamic viscosity, $\mathrm{K}$ is the intrinsic permeability, and $\mathbf{g}$ is the gravitational force. Capillary pressure and relative permeabilities are calculated using Brooks-Corey [23] relationships.

Conservation equations for coal, five immobile biofilm-components as well as for attached and thereby inactive amendment are expressed by Equation (3):

$$
\frac{\partial}{\partial t}\left(\phi^{\varphi} \rho^{\varphi}\right)=q^{\varphi},
$$

with $\varphi$ indicating whether coal, biofilm component or amendment is used. Here, $\phi^{\varphi}$ is the volume fraction, $\rho^{\varphi}$ is the mass density and $q^{\varphi}$ is the source term due to biogeochemical reactions, growth, decay or attachment/detachment of the solid phase $\varphi$. Component source and sink terms are calculated using biomass and component-dependent yield reaction terms for each microbial conversion (see Section 3.1 in Emmert et al. [14]). The porosity and permeability of the system change depending 
on the consumption of coal as well as on growth, decay, attachment, and detachment of biofilm following Hommel et al. [21].

For the numerical case study with attaching and detaching microbial cells, the transported cells are handled as inactive tracer-like components and are thereby transported with the Darcy velocity (see Equation (2)) until they attach.

\subsection{Experimental Results}

Davis et al. [8] investigated methane production under continuous-flow conditions in four column reactors. All columns were packed with coal initially and inoculated with microbial consortia prepared equivalently to the batch experimental and numerical studies [5,14]. In the following, a " + " stands for amendment addition and a "-" for no amendment addition at Day 0 or Day 61. "Coal" indicates that the column was operated with coal as a porous medium, where we assume $0.5 \%$ of the carbon in the coal to be available for bioconversion to methane [14]. Two reactors $\left(\mathrm{Coal}^{++}\right.$and Coal $\left.{ }^{+-}\right)$were amended initially with algal biomass, while the other reactors remained unamended. Out of those two, only Coal ${ }^{++}$was amended again on Day 61. The reactors with amendment additions on Day 0 produced methane continuously at a similar rate, regardless of whether they were amended a second time or not. Two other reactors (Coal ${ }^{-+}$and $\mathrm{Coal}^{--}$) did not receive amendment on Day 0, but Coal ${ }^{-+}$ received an amendment addition on Day 61. The unamended reactor $\left(\mathrm{Coal}^{--}\right)$never produced gas, while the reactor that was only amended on Day $61\left(\mathrm{Coal}^{-+}\right)$showed delayed and little methane production over the duration of the experiment. The latter two reactors will not be investigated in the model as the available data are too sparse to improve the model in a meaningful way at this point.

With these experimental results, and taking into account ${ }^{13} \mathrm{C}$ gas analysis, Davis et al. [8] conclude that methane generation in the column is primarily from coal-to-gas conversion with minimal contributions to gas production from amendment-to-gas conversion. This leads to two primary hypotheses being investigated using the developed numerical model.

- Hypothesis 1 states that not all amendment is transported into or through the column but might have been trapped in the inlet region of the column during the injection. This could lead to the second amendment addition effectively not reaching the column at all and thereby explaining the almost identical behavior of reactors $\mathrm{Coal}^{++}$and $\mathrm{Coal}^{+-}$.

- Hypothesis 2 states that with flow and transport occurring in the column, microbial cells need to attach to the coal surface and grow. This process is slower than in the batch experiments reported in Davis et al. [5] and Emmert et al. [14].

\subsection{Numerical Model}

The numerical model is set-up in the porous medium flow simulator $\mathrm{DuMu}^{\mathrm{x}}[24]$ and is an extension of the biogeochemical model proposed in Emmert et al. [14]. This batch model uses a food web with substrate-specific types of bacteria to model the conversion of coal and amendment to intermediate products (acetate, hydrogen and methyl groups). One bacterial group is considered to only consume the coal (referred to as "coal-consuming" bacteria), while the other group can convert the amendment as well as coal (referred to as "coal and amendment-consuming" bacteria). Only $0.5 \%$ of the coal's C-content is assumed to be available for bioconversion [4]. This assumption was already used in the calibration of the batch model [14] and holds locally in each grid cell of the discretized model domain. In the following, amendment and the bioavailable fraction of coal are referred to as the "main substrates" because they are converted to intermediate products that are converted to methane in the model. The intermediate products are converted by specialized archaea that perform methanogenesis and, in general, produce methane and $\mathrm{CO}_{2}$. Each bacterial or archaeal group is considered as a biofilm in the model, and they are all occupying pore space in the column.

With our numerical setup, we can now model flow and transport through a lab-scale column. The modeled column is a simplified abstraction of the experimental setup from Davis et al. [8] without inlet and outlet regions. It is $0.139 \mathrm{~m}$ in height, has a diameter of $0.0525 \mathrm{~m}$, and consists of an inflow 
boundary at the bottom and an outflow (fixed pressure) at the top while lateral boundaries are Neumann no-flow. We are using a fully coupled and fully implicit discretization in time and space, and everything is solved monolithically with the help of $\mathrm{DuMu}^{\mathrm{x}}$. In detail, we use a cell-centered finite-volume scheme in space and the implicit Euler method is applied for time. The resulting system is linearized using the Newton-Raphson method and solved using BiCGStab [25]. The dune-foamgrid module [26] is used to generate a one-dimensional abstraction of the three-dimensional column for modeling with 80 grid cells.

Depending on the modeling setup, the inflow boundary conditions are adapted over time, resulting in four different modeling cases: Case 1: Homogeneously distributed biofilm with pulse-like amendment additions. Case 2: Homogeneously distributed biofilm with stretched-out amendment additions (inlet clogging). Case 3: Homogeneously distributed biofilm with amendment additions, filtration and amendment retardation effects. Case 4: Injected microbial cells with amendment additions, filtration and amendment retardation effects.

The different modeling cases with their respective parameters, added amendment and/or biofilm, are also illustrated in Figure 1. A constant water injection representing the experimental flow rate of $0.005 \mathrm{~mL} / \mathrm{min}\left(8.33 \times 10^{-11} \mathrm{~m}^{3} / \mathrm{s}\right)$ is applied for all modeling cases at the inflow boundary. The amendment additions might occur on Day 0 and Day 61. If there is only one amendment addition on Day 0 , it is depicted with the dashed lines that mostly are covered by the two amendment addition cases which are represented by solid lines. The biofilm addition for Case 4 only occurs once on Day 0 , while biofilm is assumed to be present homogeneously throughout the column for all other Cases.

With these cases, we investigate the different hypotheses. Case 1 serves as a reference for what a well-established flow simulator coupled to the batch-reaction system (with minor modifications in the biofilm distribution) computes as a result. Case 2 builds on the post-experimental observation that the inlet region of the column potentially was clogged with an amendment or biofilm [8]. To translate this into the model, we assume that the amendment is not added as a single pulse, but each amendment addition is stretched out over 61 days. This means we inject the same total amount of amendment, but in small continuous portions over 61 or 121 days and assume no retardation inside the column. Case 3 addresses the same experimental observation as Case 2 with respect to the clogging in the inlet region; however, in this case, a filtration model is implemented for clogging or retardation of the amendment inside the column. Case 4 is, computationally, the most challenging case, as we now implement microbial cell attachment and detachment, while also using the amendment filtration from Case 3. This introduces additional complexity to the model, but we consider it to be the most realistic scenario since in the experiments the inoculum was also injected. The relevant modeling parameters are given in Table 1, while the complete overview of all numerical and physical parameters is in Table A1 (Appendix A).

Table 1. Parameters for the simulation cases derived from Davis et al. [8]. Decay rate coefficient are taken or adapted from Emmert et al. [14] and attachment-detachment coefficients are estimated and fitted to match the experimental study.

\begin{tabular}{ccc}
\hline Parameter & Value & Unit \\
\hline Column length & 0.139 & {$[\mathrm{~m}]$} \\
Column diameter & 0.0525 & {$[\mathrm{~m}]$} \\
Porous medium porosity & 0.48 & {$[-]$} \\
Flow rate & $8.33 \times 10^{-11}$ & {$\left[\mathrm{~m}^{3} / \mathrm{s}\right]$} \\
Decay rate coefficient Cases 1-3 & $1 \times 10^{-3}$ & {$\left[\mathrm{~d}^{-1}\right]$} \\
Decay rate coefficient Case 4 & $1 \times 10^{-4}$ & {$\left[\mathrm{~d}^{-1}\right]$} \\
Amendment attachment coefficient Case 3 $\lambda_{\text {attach, } \mathrm{C3}}^{\text {Am }}$ & $2.52 \times 10^{4}$ & {$\left[\mathrm{~m}^{-1}\right]$} \\
Amendment detachment coefficient Case 3 $\lambda_{\text {detach, } \mathrm{C} 3}^{A m}$ & $1.12 \times 10^{-4}$ & {$\left[\mathrm{~s}^{-1}\right]$} \\
Amendment attachment coefficient Case $4 \lambda_{\text {attach, } \mathrm{C} 4}^{\text {Am }}$ & $5.14 \times 10^{4}$ & {$\left[\mathrm{~m}^{-1}\right]$} \\
\hline
\end{tabular}


Table 1. Cont.

\begin{tabular}{ccc}
\hline Parameter & Value & Unit \\
\hline Amendment detachment coefficient Case $4 \lambda_{\text {detach }, C 4}^{A m}$ & $4.96 \times 10^{-6}$ & {$\left[\mathrm{~s}^{-1}\right]$} \\
Cell attachment coefficient Case $4 \lambda_{\text {attach, } \mathrm{C} 4}^{\text {Bio }}$ & $7.51 \times 10^{5}$ & {$\left[\mathrm{~m}^{-1}\right]$} \\
Cell detachment coefficient Case $4 \lambda_{\text {detach, } \mathrm{C} 4}^{\text {Bio }}$ & $1.11 \times 10^{-8}$ & {$\left[\mathrm{~s}^{-1}\right]$} \\
\hline
\end{tabular}

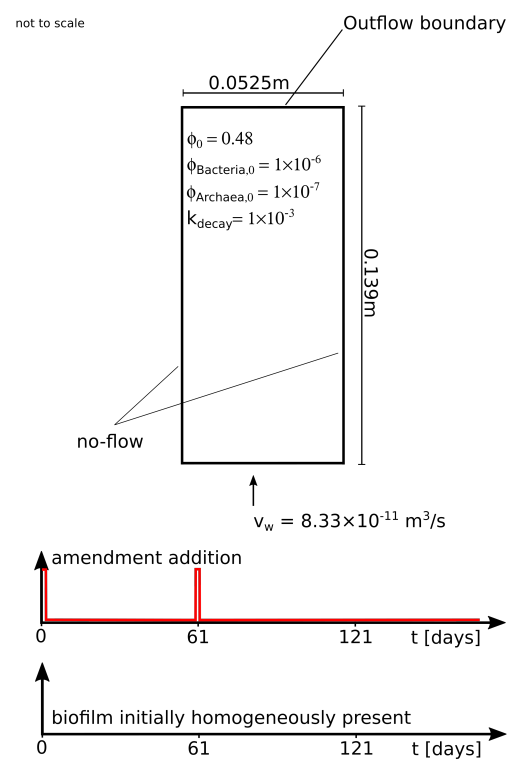

(a) Setup and parameters for Case 1.

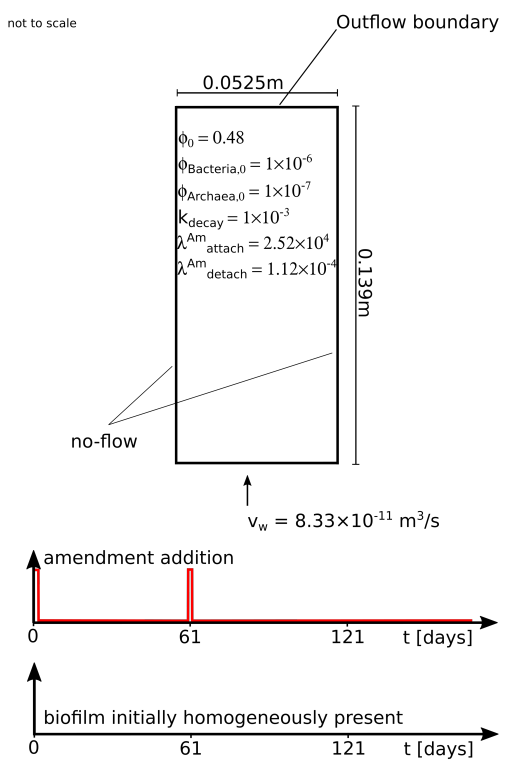

(c) Setup and parameters for Case 3.

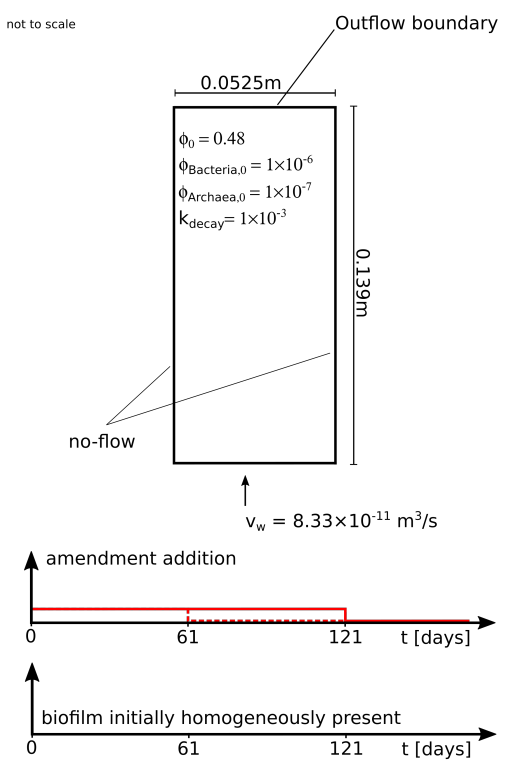

(b) Setup and parameters for Case 2.

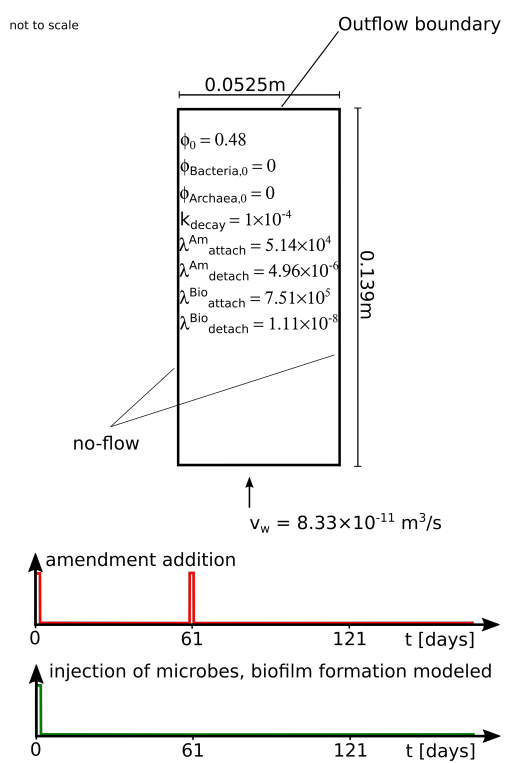

(d) Setup and parameters for Case 4.

Figure 1. Visualization of the model setup for the different cases and relevant the corresponding relevant parameters for all cases. The inclusion of retardation of amendment, as well as attaching and detaching microbial cells, involves additional attachment and detachment parameters. All unchanged Parameters are given in Table A1. 


\subsection{Processes}

This numerical study aims at reproducing experiments by Davis et al. [8]; however, the calibration of the model is not straightforward because the experimental data are not as abundant as in the batch studies performed previously by the same group [5]. Multiple processes occur simultaneously, hence the experimental evidence does not always allow unique conclusions. With different simulation scenarios, we use the flexibility of the model to analyze the processes and to contribute to the discussion, thus improving the understanding of the processes that occur.

Processes that might have an impact on the $\mathrm{CH}_{4}$ generation in the column include changes in the reaction system due to the flow, amendment retardation in the sense of inlet clogging or filtration and thereby retardation effects in the column, cell attachment and detachment due to flow as well as combinations of all mentioned processes. The previous sections describe very basic approaches to model these processes. We note that we intend to keep the complexity of the processes as simple as possible, even though more sophisticated and more parametrized approaches might be available in certain cases. Therefore, when it comes to changes in the reaction system due to the flow, we assume that an observed decrease in production rates, in comparison with batch systems, could be modelled in different ways. One option would be to consider a reduced activity of the biofilm. This can be achieved in the model by reducing the volume fractions of initial biofilm, reducing growth rates or increasing decay rates. Another mechanism for achieving reduced production rates could include incomplete mixing in the columns, i.e., substrates are not available equally well as in the batch systems. In any case, the coupled flow, transport, and reaction model inherently account for a reduction of concentrations due to transport. Of course, one might, for example, furthermore decrease reaction yields. We note here that we are well aware of the complexity that our model has, and, given the limited amount of experimental data, we restrict ourselves to including only those mechanisms which we think are most relevant. Eventually, we try to model the changes in methane production mainly with biofilm properties, i.e., detachment, decay due to shear stress or less active biofilm; and we assume thereby that the same reactions as obtained from the batch systems now coupled to flow and transport can represent the effect on the total methane production.

\subsubsection{Retardation and Filtration}

Modeling retardation and filtration processes in porous media can be considered on the micro or macro scale. Good overviews of deep-bed filtration and the corresponding mechanisms are given in [15-17]. Since the model in this study is based on the REV concept, we will focus on the macro-scale description of retardation and filtration processes. Many numerical studies have been performed with respect to filtration processes and there are different approaches and equations with different levels of complexity available. Since this study is the first step towards a more realistic description of the MECBM process and many different processes are of potential importance, we focus on a very basic description of filtration that is coherent in most filtration concepts.

We describe the particle retention rate of a particle $\kappa$ as a rate $r^{\kappa}$ added to the source term $q^{\kappa}$ (see Equation (1)) in Equation (4):

$$
r^{\kappa}=\lambda_{\text {attach }}^{\kappa} C_{w}^{\kappa} v_{w},
$$

where $\lambda_{\text {attach }}^{\kappa}$ is the attachment or filtration coefficient of component $\kappa, C_{w}^{\kappa}$ is the concentration of a component in the aqueous phase, which is calculated from $C_{w}^{\kappa}=x_{w}^{\kappa} \rho_{m o l, w} M^{\kappa}$, and $v_{w}$ is the aqueous phase velocity. $\lambda_{\text {attach }}^{\kappa}$ is usually dependent on the structure of the porous medium, the flow properties and interactions between the particles. Many models, ranging from basic [27,28] to more advanced [29] have been proposed; however, we use a simple form of Equation (4) and do not account for more complex calculations of $\lambda_{\text {attach }}^{\kappa}$ for now. The process of attachment or detachment is modeled by adding the rate $r^{\kappa}$ to the equivalent solid source term $q^{\varphi}$ which corresponds to $\kappa$. Thus, every component $\kappa$ has an equivalent solid part $\varphi$. 
Since we assume that the particles are not only attaching to the porous medium but can also be resuspended and transported with the mobile phases again, the process we model is rather a mixture between filtration and partitioning or retardation [17].

In general, we assume that detachment is proportional to the shear stress. Shear stress is actually not represented in our macro-scale (REV-scale) model concept. Thus, it has to be considered on the macro-scale by an effective process that upscales the micro-scale effects. We use here the aqueous-phase potential gradient following Rittman's [30] general model of biofilm shearing with [31]. Rittman model and parameters could be improved through further knowledge about the type of biofilm, however this is beyond the scope of this study, which is why we keep the variable parameters for fitting at a minimum and stay with this approach in Equation (5):

$$
r^{\varphi}=k_{\text {detach }}^{\varphi} \phi^{\varphi} \rho^{\varphi}
$$

where we describe the rate of detachment $r^{\varphi}$ of solid $\varphi$ mainly with a detachment coefficient for this solid $k_{\text {detach }}^{\varphi}$. For the amendment, this detachment coefficient $k_{\text {detach }}^{\varphi}$ is defined in Equation (6):

$$
k_{\text {detach }}^{\varphi}=\lambda_{\text {detach }}^{\varphi}\left(\phi S_{\mathrm{w}}\left|\nabla p_{\mathrm{w}}-\rho_{\mathrm{w}} \mathbf{g}\right|\right)^{0.58} .
$$

Here, $\lambda_{\text {detach }}^{\varphi}$ is the detachment or resuspension coefficient of solid component $\varphi$ due to shear stress.

\subsubsection{Cell Attachment and Detachment}

Cell attachment in porous media is a different process than retardation or filtration of amendment. However, the mechanistic description is similar in the way the equations are used in the model. Therefore when modeling cell attachment, we also use Equation (4) with a different $\lambda_{\text {attach }}^{\kappa}$ than for the amendment, as the cell attachment mechanisms of suspended cells $\kappa$ might be different depending on the type of cell. However, we do not have further experimental information on the cell types and model all microbial cells with the same estimated and calibrated $\lambda_{\text {attach }}^{\kappa}$.

For cell detachment, we also use Equation (5), but calculate the detachment coefficient with an extended relation derived from [32]:

$$
k_{\text {detach }}^{\varphi}=\lambda_{\text {detach }}^{\varphi}\left(\phi S_{w}\left|\nabla p_{w}-\rho_{w} \mathbf{g}\right|\right)^{0.58}+\frac{\phi^{\varphi}}{\phi} \mu_{\mathrm{g}}^{\varphi},
$$

where the volume fraction of the respective biofilm $\phi^{\varphi}$ is set in relation to the porosity $\phi$ and the growth rate $\mu_{\mathrm{g}}^{\varphi}$ of the biofilm $\varphi$ in addition to detachment as defined in Equation (6).

\subsubsection{Biofilm Modifications Due to Flow}

In this study, different modeling setups with and without cell attachment or detachment are investigated. The assumptions made in the model, such as reaction kinetics growth and decay rates are taken from Emmert et al. [14], which is calibrated using batch experiments without flow and transport. Shear stress, induced by flow through the column, might have an impact on the biofilm, as parts of the biofilm can detach and potentially decay. Additionally, biofilms might not grow as abundantly due to dilution of required components. For modeling setups that do not account for cell attachment or detachment (Cases 1, 2, and 3), the decay rate of biofilm is increased by an order of magnitude from $10^{-4} \mathrm{~d}^{-1}$ to $10^{-3} \mathrm{~d}^{-1}$. This is assumed to account for some potential inactivation or additional decay under flow conditions relative to batch experiments. This is performed for these cases to better match the first 50 days of the numerical study to the experimental results. Additionally, the active biofilm volume fraction initially presents along the entire column is reduced by up to an order of magnitude. 


\section{Results}

We describe the four different cases introduced in Section 2.3 individually here. The model is compared only to two experimental setups with an initial amendment addition. As previously described, the other experimental results showed minimal or no methane production and are not included in the comparison study here.

The experimental data (see e.g., Figure 2a) show a relatively continuous increase in cumulative methane production from the column starting from Day 25 or 30 and increases to $0.0017 \mathrm{~mol}$ or 0.0015 mol for Exp Coal ${ }^{++}$(blue dots) or Exp Coal ${ }^{+-}$(black dots). Even though a second amendment addition was performed on Day 61 for Exp $\mathrm{Coal}^{++}$, the experimental data do not show a substantial increase in methane production after Day 61 compared to Exp Coal ${ }^{+-}$. As the experimental study by Davis et al. [8] stops after 172 days, no further data are available for comparison. It is thus not clear from this study when and at what amount cumulative methane production would level out.

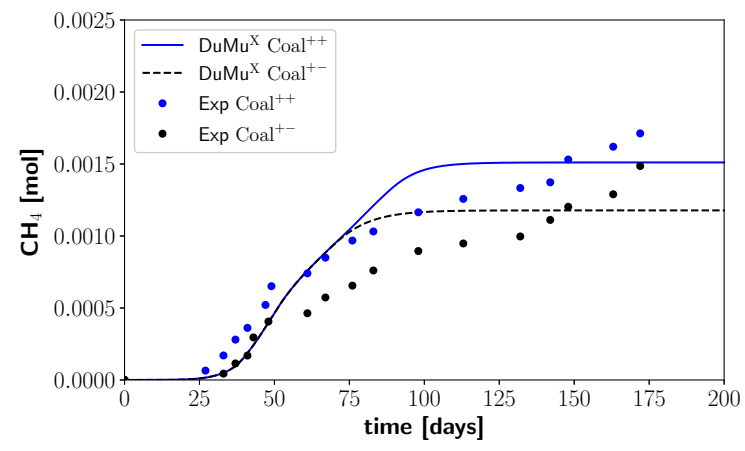

(a) Methane production.

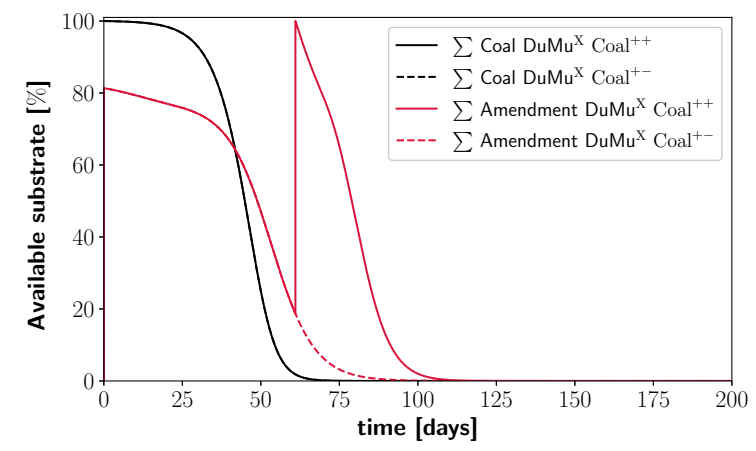

(b) Substrate availability.

Figure 2. Results of Case 1 with homogeneously distributed biofilm and pulse-like amendment additions on Day 0 and Day 60. (a) Methane production of the column over the time of the DuMu model compared to the experimental results. Blue is the scenario with two amendment additions $\left(\mathrm{Coal}^{++}\right)$, black with only one addition $\left(\mathrm{Coal}^{+-}\right)$. (b) The corresponding substrate availability for coal (black) and amendment (red). For the plot, the substrate is summed over the entire column and plotted as a percentage of what is maximally available during the simulation. Here $\mathrm{DuMu}^{\mathrm{x}} \mathrm{Coal}^{++}$is depicted with a solid line and $\mathrm{DuMu}^{\mathrm{x}} \mathrm{Coal}^{+-}$with a dashed line.

We evaluate the model until Day 200 for all modeling cases and assess the agreement with the available experimental data. However, for the amendment retardation as well as for the cell attachment and detachment cases, additional figures with up to 600 or 1050 days are provided. This is done, as not all amendment and coal is consumed at the end of the 200-day study. Therefore, methane production from the column has not stopped either and we want to investigate the model response over the entire theoretical time of methane production. Additionally to the methane production over time, the substrate availability is plotted. Substrate availability means that the relative abundance of the two main substrates (coal and amendment) is investigated for each study. To facilitate the comparison, their local concentration or volume fraction at each point in the column is summed over the entire column and plotted as a percentage of what is maximally available during the simulation. However, information on where in the column the substrate is still available cannot be presented for this type of plot.

The parameters used for simulations are given in Table 1. Where applicable, modifications to the biofilm decay rate and initial distribution are explained in Section 2.4.3. All reaction kinetics and processes are from the validated batch model defined in Emmert et al. [14]. 


\subsection{Case 1: Homogeneously Distributed Biofilm, Pulse-Like Amendment}

The first modeling case uses the batch kinetics with minor adjustments in the biofilm decay rate and initial biofilm presence. The results of the cumulative methane production at the top of the column are shown in Figure 2a. The blue curve shows methane production for the $\mathrm{DuMu}^{\times} \mathrm{Coal}^{++}$case as a result of the model. Methane production is first detectable in the columns on Day 24 and a gradual increase can be seen from Day 30 until approximately Day 80. After that, methane production levels out at $0.0015 \mathrm{~mol}$.

The black curve shows methane production for the $\mathrm{DuMu}^{\times} \mathrm{Coal}^{+-}$case and is identical to the $\mathrm{DuMu}^{\times} \mathrm{Coal}^{++}$case for the first 61 days. Since there is no second amendment addition on Day 61, the methane production of $\mathrm{DuMu}^{\times} \mathrm{Coal}^{+-}$slows down after Day 61 and levels out after Day 100 at $0.0012 \mathrm{~mol}$.

Figure $2 \mathrm{~b}$ shows the two main substrates, coal and amendment, available in the column over time in a normalized way. The coal is given with the black curves for $\mathrm{DuMu}^{\mathrm{x}} \mathrm{Coal}^{++}$and $\mathrm{DuMu}^{\mathrm{x}} \mathrm{Coal}^{+-}$. The two setups coincide and their behavior is very similar for this case. We see only slow conversion of coal for the first 30 days, after that the microbial community has grown sufficiently to rapidly consume the coal. After Day 55 the conversion of coal slows down, as less substrate is available for the biofilm, before all coal has been consumed on Day 70 .

Amendment on the other hand is injected for $\mathrm{DuMu}^{\times} \mathrm{Coal}^{++}$on Day 0 and Day 61. The peak amendment concentration occurs at the second amendment addition on Day 61 for this column. Therefore, when normalizing amendment concentrations, the initially available amendment fraction is only at $81 \%$. The added amendment is consumed and transported slowly until Day 35 . From then on, the amendment is also transported out of the column unused. Therefore, the fraction of the available amendment decreases faster now. On Day 61, the second amendment addition occurred and the maximum amount of amendment is present in the column. The decrease of amendment occurs as fast as from Day 50 to Day 61, which is mainly attributed to the conversion of the newly added amendment to intermediate products by the coal and amendment-consuming bacteria in the biofilm and partially to the remaining amendment and its intermediate products from the first amendment additions. On Day 80, the second amendment addition starts being washed out of the column, while the conversion of an amendment to intermediate products still occurs. This leads to a steeper slope of amendment availability, before leveling out at approximately Day 90 . All substrate (coal and amendment) is consumed after Day 110.

When comparing Figure $2 \mathrm{a}, \mathrm{b}$, it is visible that the initial increase in methane production is primarily driven by the conversion of coal and amendment. With the coal being consumed everywhere along the column and running out after Day 60, we also see a less steep slope in the methane production in Figure 2a. Now, mostly amendment is converted and the slope in the methane-production curve stays the same before it levels out around Day 80 .

The overall match to the experimental results is reasonable for the first 75 days, as the modeling curve and the experimental data coincide in Figure 2a. However, after Day 75, a distinct difference between $\mathrm{DuMu}^{\times} \mathrm{Coal}^{++}$and $\mathrm{DuMu}^{\times} \mathrm{Coal}^{+-}$is visible for the modeling study, where the methane production of $\mathrm{DuMu}^{\times} \mathrm{Coal}^{+-}$levels out, while the methane production of $\mathrm{DuMu}^{\times} \mathrm{Coal}^{++}$increases further due to the second amendment addition. This is in contrast to the experimental studies Coal ${ }^{++}$ and $\mathrm{Coal}^{+-}$, that behave similarly to one another. The cessation of methane production predicted by the model is not seen in the experiment and is explained in the model with all available substrate being consumed. Without substrate for the microbes, no further methane generation is possible in the model.

\subsection{Case 2: Homogeneously Distributed Biofilm, Continuous Amendment Injection}

The second modeling case is using the same setup as the first case, but now the amendment is not injected as a pulse, but rather the injection is stretched out over 61 days. This aims at imitating a clogging or localized retention of the amendment at the inlet, that might have happened during the experiment [8]. The results of the cumulative methane production are shown in Figure 3a. The blue 
curve shows methane production for the $\mathrm{DuMu}^{\mathrm{x}} \mathrm{Coal}^{++}$Case as a result of the model. The first detectable methane production of the column is on Day 26 and a gradual increase can be observed until approximately Day 80, after which methane production levels out at $0.0023 \mathrm{~mol}$.

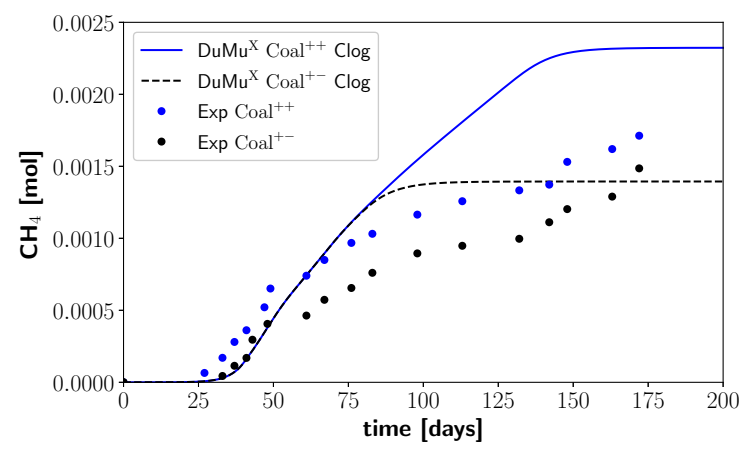

(a) Methane production.

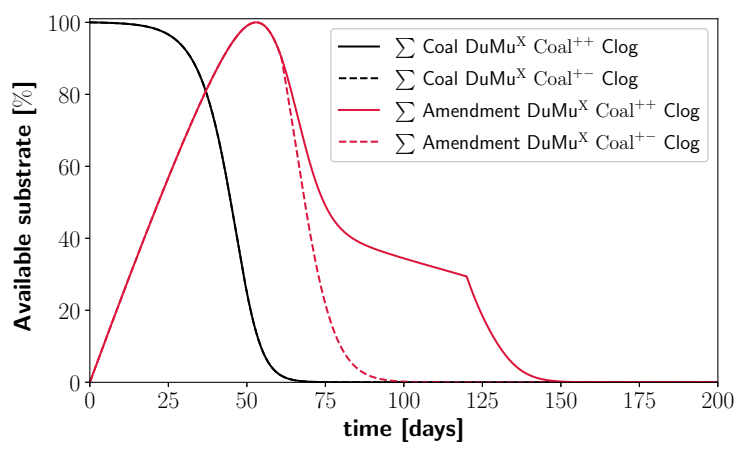

(b) Substrate availability.

Figure 3. Results of Case 2 with homogeneously distributed biofilm and stretched out amendment additions. (a) Methane production of the columns over time of the DuMux model compared to the experimental results. Blue is the scenario with two amendment additions ( $\mathrm{Coal}^{++}$), black with only one addition $\left(\mathrm{Coal}^{+-}\right)$. (b) The corresponding substrate availability for coal (black) and amendment (red). For the plot, the substrate is summed over the entire column and plotted as a percentage of what is maximally available during the simulation. Here $\mathrm{Coal}^{++}$is depicted with a solid line and Coal ${ }^{+-}$ with a dashed line.

The black curve shows methane production for the $\mathrm{DuMu}^{\mathrm{x}} \mathrm{Coal}^{+-}$Case and is identical to the $\mathrm{DuMu}^{\times} \mathrm{Coal}^{++}$Case for the first 61 days. As before, $\mathrm{DuMu}^{\mathrm{x}} \mathrm{Coal}^{+-}$ceases production after 100 days at approx. $0.0014 \mathrm{~mol}$.

Figure $3 \mathrm{~b}$ shows the two main substrates (coal and amendment) available in the column over time in a normalized way. Coal is given with the black curves for $\mathrm{DuMu}^{\mathrm{x}} \mathrm{Coal}^{++}$and $\mathrm{DuMu}^{\mathrm{x}} \mathrm{Coal}^{+-}$. The two setups coincide and behave in the same way for this case. The consumption of coal is almost identical to Case 1, as the initial coal and biofilm distributions are the same.

Only the amendment injection is varied, which leads to minimal changes in coal consumption because parts of the bacteria can grow on coal and amendment. The amendment is injected for the $\mathrm{DuMu}^{\times} \mathrm{Coal}^{++}$Case on Day 0 and Day 61. We see a quasi-linear increase of methane for the first 54 days before more amendment is consumed and washed out than is being injected. After this peak on Day 54, a large part of the amendment is being washed out of the column, while at the same time being consumed for the next 25 days. On Day 80, approximately $40 \%$ of the amendment is available in the column, but since the microbes along the entire column have grown with the continuous feeding, the newly added amendment does not reach the end of the column anymore, but is being consumed in the influent region of the $\mathrm{DuMu}^{\times} \mathrm{Coal}^{++}$column. This combination of amendment injection and consumption in the column leads to the slower decrease of the available amendment until Day 121. On Day 121, the continuous amendment addition stops and the remaining amendment is consumed within a short time. On Day 150, no substrate (coal and amendment) is left in the column.

For the $\mathrm{DuMu}^{\times} \mathrm{Coal}^{+-}$study, the amendment is only injected continuously from Day 0 to Day 61 . Therefore, the curves of $\mathrm{DuMu}^{\times} \mathrm{Coal}^{++}$and $\mathrm{DuMu}^{\mathrm{x}} \mathrm{Coal}^{+-}$coincide for the first 61 days. After this, the available amount of amendment for the $\mathrm{DuMu}^{\times} \mathrm{Coal}^{+-}$study decreases rapidly for the same reasons given above. The microbial community has grown and consumes the remaining amendment completely by Day 80 .

When comparing Figure 3a,b next to each other, the initial increase in methane production is primarily driven by the conversion of coal and amendment. With the coal being consumed everywhere along the column and running out after Day 60, we again see a less steep slope in the methane 
production in Figure 3a after Day 60. Now, mostly amendment is converted and the slope of the methane-production curve stays the same before it levels out.

A reasonable match to the experimental results is given for the first 60 days, as the modeling curve and the experimental data coincide in Figure 3a. However, after Day 60, both modeling studies show a larger methane increase than the experimental results. $\mathrm{DuMu}^{\times} \mathrm{Coal}^{++}$and $\mathrm{DuMu}^{\times} \mathrm{Coal}^{+-}$level out due to substrate depletion after 140 or 100 days respectively, whereas the experimental studies do not exhibit such a behavior.

\subsection{Case 3: Homogeneously Distributed Biofilm, Amendment Retardation}

The third modeling case has the same homogeneous biofilm distribution along the column as Cases 1 and 2, and uses a pulse-like amendment injection. In contrast to Cases 1 and 2, it uses a filtration law to model amendment retardation and partitioning as described in Equation (4). The results of the cumulative methane production at the top of the column are shown in Figure $4 \mathrm{a}, \mathrm{c}$ to show all the modeling data. The blue curve shows the predicted methane production for the $\mathrm{DuMu}^{\mathrm{x}} \mathrm{Coal}^{++} \mathrm{Case}$. The first methane production at the end of the column is on Day 21 and a gradual increase can be seen from Day 30 until approximately Day 60. After that, methane production rates slow down temporarily until Day 470 (Figure 4c) due to the amendment being released along the column in regions where no large portions of the amendment and coal-consuming bacteria are present yet. With more amendment being released further downstream the column, amendment and coal-converting bacteria can grow and produce more intermediate products, which in turn leads to a re-increase in methane production. After Day 470 a final increase can be observed, before the methane production levels out at $0.003 \mathrm{~mol}$.

The black curve shows methane production for $\mathrm{DuMu}^{x} \mathrm{Coal}^{+-}$and is identical to $\mathrm{DuMu}^{\mathrm{x}} \mathrm{Coal}^{++}$ for the first 61 days. DuMu ${ }^{x} \mathrm{Coal}^{+-}$shows a slower increase in methane production from Day 61 until approximately Day 550. The most trapped amendment has already been released from the first part of the column and the bacteria converting both coal and amendment have not grown enough in the second part yet. Therefore, the most released amendment is transported further downstream, leads to new growth of amendment and coal-consuming bacteria and to the production of some intermediates along the column. With the bacteria established in the second part of the column, the further released amendment parts are now being mostly converted and the last stretch of the methane production increases again to a total production of $0.002 \mathrm{~mol}$.

Figure $4 \mathrm{~b}$, d show the two main substrates (coal and amendment) available in the column over time in a normalized way. Coal is given with the black curves for $\mathrm{DuMu}^{\mathrm{x}} \mathrm{Coal}^{++}$and $\mathrm{DuMu}^{\mathrm{x}} \mathrm{Coal}^{+-}$. The two setups coincide and behave in the same way for this setup. The consumption of coal is now even faster than in Cases 1 and 2, as the initial coal and biofilm distribution is the same, but the amendment is added as pulse, is trapped and then released continuously. This amendment retardation leads to a more continuous release of the amendment, which boosts the growth of microbes that convert both amendment and coal. Therefore, the consumption of the bioavailable portion of coal is completed 10 days earlier than in Cases 1 and 2.

Bioavailable amendment (red) is added for the DuMu${ }^{\times} \mathrm{Coal}^{++}$Case on Day 0 and Day 61. With the amendment filtration processes described in Equation (4), most amendment is trapped in the first part of the column initially. We see that the trapped amendment (orange) starts at almost $50 \%$, while the active and bioavailable amendment is at only 5\% for the first 61 days. Both the trapped and the bioavailable amendment decrease over the first 61 days, before the second amendment addition increases the amendment levels to the highest level during this modeling scenario, (i.e., 100\%) for the trapped amendment, and $12 \%$ for the active amendment. The pulse-like addition leads to more than $80 \%$ trapping of the amendment in a short time. This reduces the porosity and the porosity reduction leads to a larger release of the trapped amendment as the velocities and shear forces increase. The amendment is now transported further downstream to the next grid cells in the model and trapped there again. Due to this trapping and release from one computational grid cell to the next, maximum positive and negative peaks in the amendment availability curves occur here on 
Day 61. The maximum amount of trapped amendment is present on Day 61 and continuously releases bioavailable amendment until approximately Day 450, before it has all been released back by Day 800 . This in turn leads to a relatively constant bioavailable amendment fraction in the column of up to $15 \%$ of what is maximally available in the column following Day 61. This fraction decreases slowly over the next 400 days and this bioavailable amendment is consumed by the microbes and vanishes completely after Day 800.

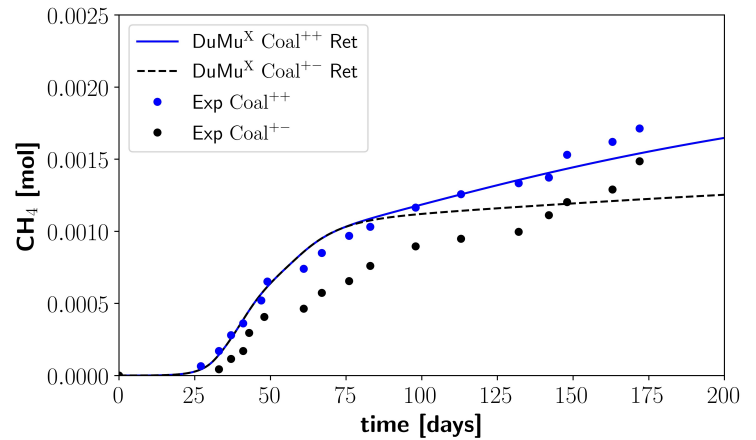

(a) Methane production (200 days).

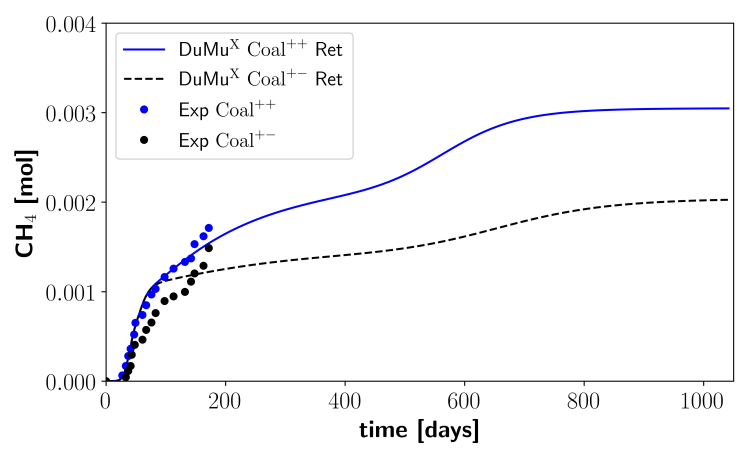

(c) Methane production (1050 days).

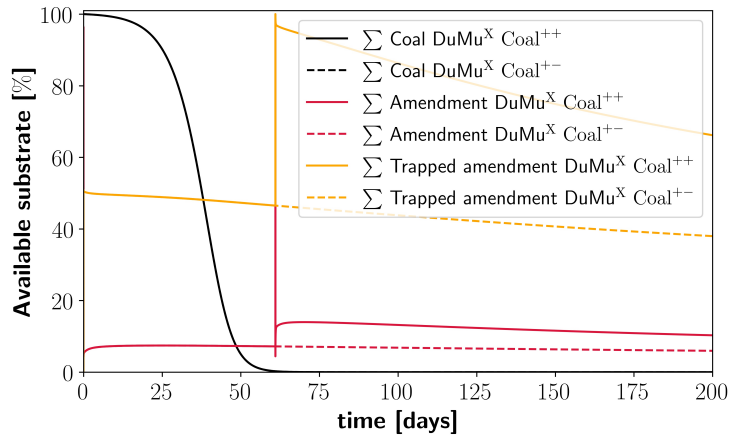

(b) Substrate availability (200 days).

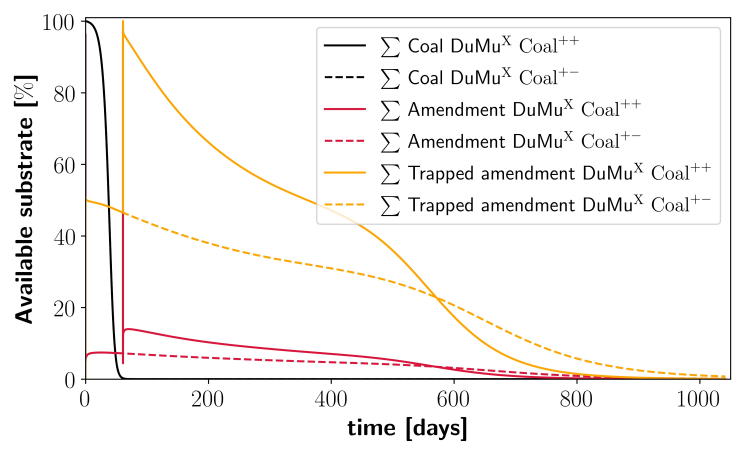

(d) Substrate availability (1050 days).

Figure 4. Results of Case 3 with homogeneously distributed biofilm and filtration and retardation effects of amendment. (a) Methane production of the columns over time of the DuMu $\mathbf{u}^{\mathrm{x}}$ model compared to the experimental results. Blue is the scenario with two amendment additions, black with only one addition. (b) The corresponding substrate availability for coal (black), amendment (red), and trapped amendment (orange). For the plot the substrate is summed over the entire column and plotted as percentage of what is maximally present during the simulation. $(\mathbf{c}, \mathbf{d})$ The same results as $(\mathbf{a}, \mathbf{b})$ until all substrate is consumed after 1050 days.

For the DuMu${ }^{\mathrm{x}} \mathrm{Coal}^{+-}$study, amendment is only injected continuously from Day 0 to Day 61. Therefore, the curves of $\mathrm{DuMu}^{\mathrm{x}} \mathrm{Coal}^{++}$and $\mathrm{DuMu}^{\mathrm{x}} \mathrm{Coal}^{+-}$coincide for the first 61 days, after which the available amount of amendment for the $\mathrm{DuMu}^{\mathrm{x}} \mathrm{Coal}^{+-}$study continues to decrease slowly until Day 800. The trapped amendment starts to decrease at a continuous rate until Day 600. From Day 600 until Day 1050, the amendment is released a little faster, as the biofilm grows, reduces porosity and thereby increases detachment rates. Almost all trapped amendment is released after 1000 days.

A comparison of Figure $4 \mathrm{c}, \mathrm{d}$ indicates that the increases in methane production are directly correlated to the release of the trapped amendment and subsequent consumption of bioavailable amendment. Mostly, amendment is converted after all coal is already consumed. The second amendment injection for $\mathrm{DuMu}^{\mathrm{x}} \mathrm{Coal}^{++}$leads to larger methane production in Figure $4 \mathrm{c}$ compared to $\mathrm{DuMu}^{\times} \mathrm{Coal}^{+-}$, while Figure $4 \mathrm{~d}$ shows that the second amendment injection results in a faster release of the trapped amendment and in turn to faster consumption of all available amendment in total. This makes sense when we consider that with the additional substrate a larger volume fraction along 
the column is occupied by microbes. Through the increased growth of microbes, a self-enhancing effect can be observed that reduces the porosity, increases the shear stress, which in turn releases more trapped amendment and ultimately enhances the growth of microbes and methane production again.

The $\mathrm{DuMu}^{x} \mathrm{Coal}^{+-}$Case seems to predict slightly higher methane production than experimentally observed for the first 150 days, followed by a slightly lower methane production after Day 150. Overall, the methane production curves match the experimental results very well. Nevertheless, one has to be careful, as most of the methane generation and production in the model is attributed to the amendment after Day 50, which is not in line with the findings of Davis et al. [8].

\subsection{Case 4: Injected Microbial Cells, Amendment Retardation}

The fourth modeling case does not assume any initial biofilm inside the column, but uses a pulse injection of microbes followed by a pulse-like amendment addition. Cell attachment and detachment are modelled using Equations (4) and (7), while amendment retardation is modelled using Equations (4) and (6).

The results of the cumulative methane production in the column are shown in Figure $5 \mathrm{a}, \mathrm{c}$. The blue curve shows methane production for the $\mathrm{DuMu}^{\mathrm{x}} \mathrm{Coal}^{++}$Case as a result of the model. The first methane production of the column is on Day 18 and a gradual increase can be seen from Day 21 until approximately Day 130. After that, methane production rates decrease temporarily until Day 210 (Figure 5c). At this time, we can observe a small kink in the curve which is related to a numerical issue. In order to understand this, one needs to keep in mind that the model can handle two fluid phases as long as they can subsist. At this point in time, the gaseous phase at the top of the column, where the pressure is the lowest, is at the brink of disappearance. This is because not enough methane is coming from the column towards the outlet of the column anymore. The model switches primary variables [33] back and forth, which leads to a discrete change in the calculation of fluxes out of the column. Essentially, the effect of this phase change is observed in methane being held back in the column for a short time, after which it is released like in a small pulse when the gaseous phase can eventually subsist again at the boundary. After this time, a short plateau with very limited methane production is observed from Day 210 until Day 250. Then, after Day 250, methane production increases again before it gradually levels out at a maximum production of 0.0019 mol on Day 550 .

The black curve shows methane production for $\mathrm{DuMu}^{\times} \mathrm{Coal}^{+-}$and is identical to $\mathrm{DuMu}^{\times} \mathrm{Coal}^{++}$ for the first 61 days. $\mathrm{DuMu}^{\times} \mathrm{Coal}^{+-}$also shows a slower methane production increase from Day 61 until approximately Day 210 when the methane production levels out at $0.0014 \mathrm{~mol}$.

Figure $5 b$,d show the two main substrates (coal and amendment) available in the column over time in a normalized way. Coal, shown in black, for $\mathrm{DuMu}^{\mathrm{x}} \mathrm{Coal}^{++}$and $\mathrm{DuMu}^{\mathrm{x}} \mathrm{Coal}^{+-}$. The two setups coincide and behave in the same way for this setup. The available coal fraction decreases fast from $100 \%$ to $92 \%$ during the first 15 days, before utilization slows down until Day 100 when $91 \%$ of the bioavailable coal fraction are still present in the system. Coal is then consumed faster again and decreases to $60 \%$ by Day 300, before it is consumed even faster until it is depleted by Day 500 .

The bioavailable amendment (red) is added on Day 0 and 61 for $\mathrm{DuMu}^{\mathrm{x}} \mathrm{Coal}^{++}$and starts at $2 \%$ for amendment on Day 0. The bioavailable amendment reaches a peak on Day 25 at $4 \%$ before it decreases to $2 \%$ again by Day 61 . With the second amendment addition, a short spike to $100 \%$ is observed, before the available amendment starts to be transported along the column until Day 80 . It then gradually decreases from 5\% until Day 200.

The trapped amendment (orange) for $\mathrm{DuMu}^{\times} \mathrm{Coal}^{++}$decreases as well, but starts initially with $80 \%$ trapped amendment. A gradual decrease to $20 \%$ is observed before the second amendment addition, and the maximum amount of trapped amendment on Day 61. Trapped amendment is released gradually until approximately Day 300, after which the remaining trapped part stays almost constant and decreases very slowly. 


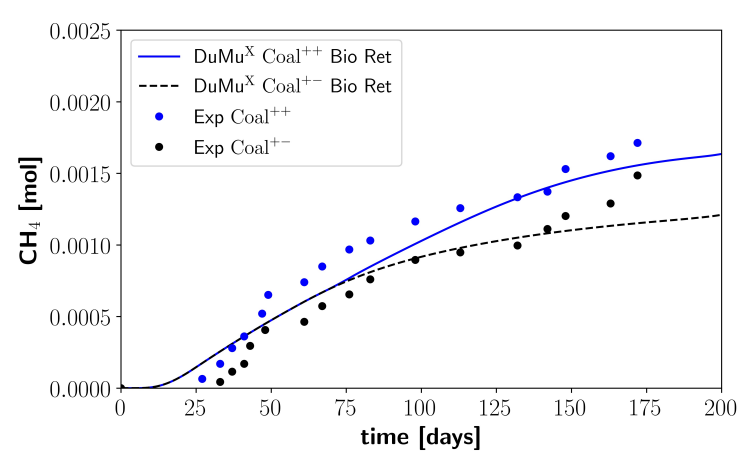

(a) Methane production (200 days).

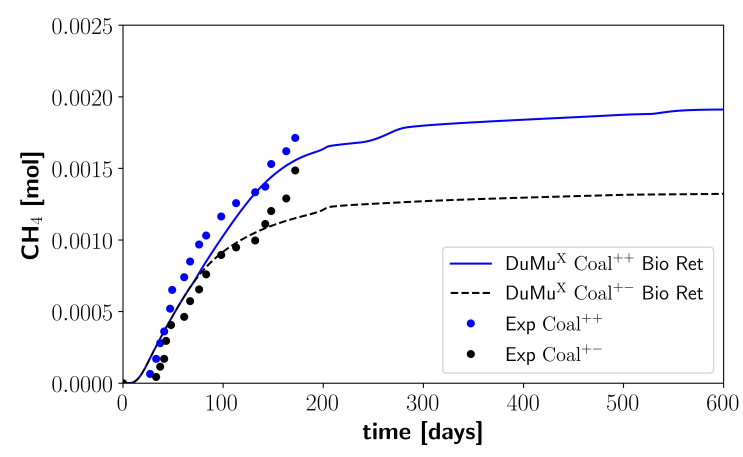

(c) Methane production (600 days).

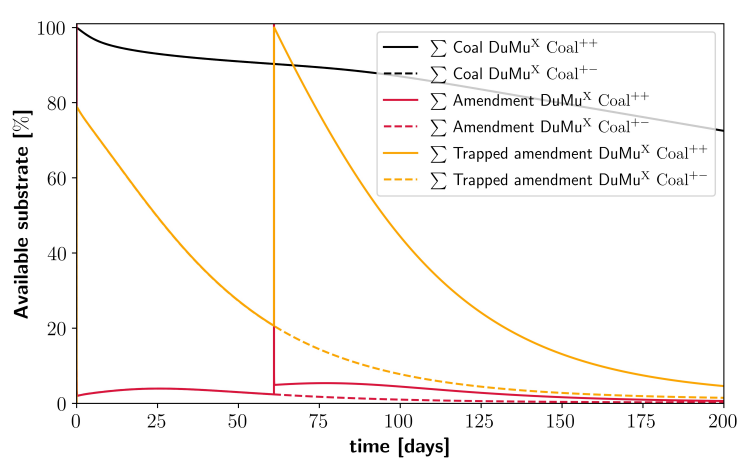

(b) Substrate availability (200 days).

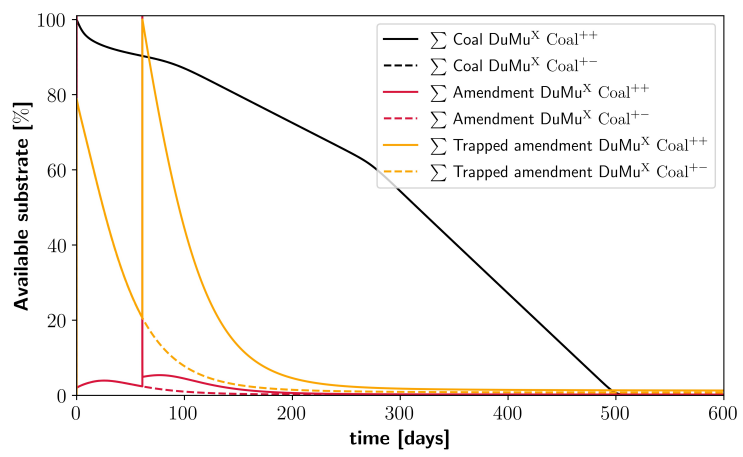

(d) Substrate availability (600 days).

Figure 5. Results of Case 4 considering injection and retardation of injected microbial cells and amendment. (a) Methane production in the columns over time of the $\mathrm{DuMu}^{\mathrm{x}}$ model compared to the experimental results. Blue is the scenario with two amendment additions, black with only one addition. (b) The corresponding substrate availability for coal (black), amendment (red), and inactive trapped amendment (orange). For the plot, the substrate is summed over the entire column and plotted as percentage of what is maximally present during the simulation. (c,d) The same results as $(\mathbf{a}, \mathbf{b})$ and predict the behaviour of the column systems out to 600 days.

Amendment availability for $\mathrm{DuMu}^{\mathrm{x}} \mathrm{Coal}^{+-}$is the same as described before and decreases after Day 61. Bioavailable amendment vanishes almost completely after Day 200. The trapped amendment for $\mathrm{DuMu}^{\mathrm{x}} \mathrm{Coal}^{+-}$deviates on Day 61 from what is described for DuMu${ }^{\mathrm{x}} \mathrm{Coal}^{++}$. Here, the trapped amendment part is being released continuously and therefore decreases until Day 200.

The overall match to the experimental results is given for $\mathrm{DuMu}^{\mathrm{x}} \mathrm{Coal}^{++}$and $\mathrm{DuMu}^{\mathrm{x}} \mathrm{Coal}^{+-}$ as the curves match the experimental results for the first 150 days. The $\mathrm{DuMu}^{\mathrm{x}} \mathrm{Coal}^{+-}$case shows a lower methane production than the experiment after Day 150. As for Case 3, the methane production curves of the model coincide with the experimental data points. Coal consumption rates appear to be in line with the findings of [8].

\section{Discussion}

The focus of this study was on combining a previously validated batch reaction model [14] with a well established flow and transport model [24], solving all equations fully implicitly and monolithically. We have strong confidence in the reliability of the flow model since it has been validated repeatedly in different benchmarking studies [34-36]. Some studies indicate that biofilms might change their composition or behavior under the influence of flow and transport [37,38], while others even report seasonal cycles [39]. Regarding biofilm in porous media, Kim et al. [40] mention that "Darcy's velocity influenced the superficial morphology of biofilm and initial time 
of clogging, whereas substrate concentration affected the biofilm density and the rate of clogging". However, a study by Fang et al. [41] reports that there is no significant change in communities' richness or diversity for river beds with static or dynamic conditions. As we model processes in porous media taking a step from a batch system to a flow-through column, we assume a difference in biofilm behavior for our systems due to either flow velocity or the different substrate concentrations due to transport of components as reported by Kim et al. [40]. Therefore, this study uses four different modeling cases to investigate various mechanisms in a comparison between one another, and, as importantly, in a comparison between the model and the available experimental data. It is an important detail to mention that the experimental study provides hints on the conversion from coal and amendment to intermediate products and to methane. Davis et al. [8] found that most of the measured methane production in the experiment can be attributed to coal. Therefore, special attention has to be given not only to the methane production, but also to how the substrates (coal and amendment) are consumed along the column.

The first modeling case, as shown in Section 3.1 and Figure 2, is the first step when moving from a batch system to a flow reactor. Other studies indicate that batch kinetics can not be simply applied to flow studies in biofilm-affected systems without consideration of decreases in reaction rates due to substrate gradients inside the pores, diffusion limitations, and non-homogeneous flow conditions [20]. Therefore, the assumption of reducing the initially present biofilm volume fraction is a crude, but effective treatment when one assumes that the biofilm activity decreases due to substrate gradients and diffusion limitations in flow systems containing attached microorganisms when moving biofilms from a batch reactor to a flow reactor. At first glance, the modeling results fit the methane production curves reasonably well, and they show that at least for the initial 100 days a model with such assumptions could theoretically produce a result that reflects the general behavior of the experiment. We argue, however, that this could build false confidence, as the methane production clearly levels out in the model after 100 days, and the substrate consumption, with all bioavailable coal being converted after 60 days, does not reflect the experimental data.

With the first case not representing the results adequately, we want to discuss in the following Hypothesis 1 (see Section 2.2) that postulates a clogged inlet and, consequently, retardation of the amendment. The modeling scenarios for Cases 2 and 3 investigate this hypothesis.

The second modelling case as shown in Section 3.2 and Figure 3 is based on the observation by Davis et al. [8] that a large amount of amendment or biofilm accumulated in the inlet region of the column. This could lead to a behavior of amendment addition that is best described in the model by a continuous addition instead of the pulse-like fashion assumed for Case 1. In this scenario, the methane-production data show a more continuous and larger increase for the first 150 days of the modeling study. The substrate-consumption study shows a more realistic outcome with slowly increasing and then decreasing amendment consumption. However, all bioavailable coal is again predicted to be consumed within the first 75 days. So even though this hard-coded change of the inlet conditions seems to enhance the model fit visually for the methane production, it still fails to match the observation of methane generation primarily from coal over the 200-day period as described in Davis et al. [8]. With these results, we do not consider Hypothesis 1 fully justified, even though the changes in the model lead to a higher and more continuous methane production than in Case 1.

The first two cases clearly consumed all bioavailable coal within the first 75 days, and thereby do not fit the experimental results as described in Davis et al. [8]. However, it is interesting to see that with a few basic assumptions the overall trend of methane production can be matched, even though major drawbacks regarding the substrates (coal and amendment) remain.

Hence, the third modeling case implemented a new feature in form of a filtration or retardation equation. We investigated Hypothesis 1 using a different approach than for Case 2, and it is shown in Section 3.3 and Figure 4, that this retention of the amendment helps in establishing a continuous methane production over a period of up to 1000 days. The trapped amendment is not available to the microbes, and thus represents local storage. Therefore, only small portions of the amendment 
are available in the column at all times and the microbial community uses most of the amendment, whereas without trapping, e.g., as in modeling Cases 1 and 2, the amendment is partially washed out of the column. The trapping of amendment supports continuous growth of the microbes along the column which in turn helps in converting most of the added amendment to methane. With the continuous release of the amendment, coal and amendment bacteria grow more continuously and convert coal and amendment. Therefore, this modeling case produces the most cumulative methane as the microbes are continuously fed by the amendment and the coal as long as it is available. All the bioavailable coal along the column is consumed within approximately 50 days, which is the shortest period for all modeling cases. However, with the already established and active biofilm in the column, the model fails to match the observation by Davis et al. [8] of slow coal conversion until the end of the experimental study. This prediction can be explained by the continuous feeding of the biofilm with amendment due to repeated retardation and release of the amendment based on changes in shear stress due to biofilm growth implemented with Equation (6). The biofilm grows faster due to the changed availability of the amendment and as a result, consumes the coal faster. This is derived from a comparison of coal consumptions from Figures $2 b, 3 b$ and $4 b$. The model predicts the coal to be consumed up to 10 days earlier for Case 3 in comparison to Cases 1 and 2. Figure $4 \mathrm{~b}$ additionally shows that amendment is mostly available at a low concentration for the microbes, whereas peaks in amendment concentration are visible for Cases 1 and 2. If at one point in the column, all bioavailable coal is converted, but amendment is still being released, the amendment is being transported downstream to support further biofilm growth. The implementation of Hypothesis 1 for Case 3 seems to approximate the results of the experimental study better than Case 2. Regarding the modeling, it also introduces additional degrees of freedom, as retardation of amendment can be adapted and fitted to the experimental results. With these findings, Hypothesis 1 is still not fully confirmed, but the implementation of amendment retardation yields a result that supports the continuous growth of the microbial community by constantly releasing small portions of amendment over a long period of time. Namely, amendment is modeled to be present in the column for approximately 1000 days in Case 3, while it vanishes after approximately 150 days in Case 2. However, this implementation of Hypothesis 1 is not in line with what Davis et al. [8] observed in the experiments; that coal is primarily converted. Thus, we have to conclude that we can not explain the results with Hypothesis 1 alone. Therefore, Hypothesis 2 needs to be evaluated and discussed.

The fourth, and last modeling case models the retardation and release of amendment as in Case 3 and additionally implements a microbial cell injection combined with cell attachment and detachment. This means, that the biofilm is not initially homogeneously distributed everywhere along the column, but is now subject to constant changes due to flow and transport. In other words, this investigates the combination of Hypotheses 1 and 2. This model adds significantly more complexity, as cell attachment and detachment are-among other processes-again dependent on the velocity, the pressure gradient, and the porosity of the column. While the first 200 days of modeling match the experimental data visually, a few remarkable changes occur: Methane production occurs earlier than for all other cases. Since we model the cells now as being injected, and, as soon as the cells attach, assume a fully-established biofilm, the volume fractions of biofilm in the influent region of the column are larger than for the other cases. All other cases only had a relatively small volume fraction of biofilm present in the beginning. If the substrate arrives, biofilms need to grow and establish their food network, before they produce large amounts of intermediates and end products. Therefore, the conversion of coal and amendment starts right away and an initial increase in methane production (Figure 5a), as well as a small but early decrease in coal availability, can be observed (Figure 5d). After this, the microbial cells gradually detach, transport downstream, and reattach to form new biofilm. This leads to the continuous methane generation in the column, and the continuous decrease in coal consumption.

For Case 4, $\mathrm{DuMu}^{\mathrm{x}} \mathrm{Coal}^{+-}$shows depletion of amendment around Day 300 and the subsequently continued methane generation can be attributed to the conversion of coal by the enriched biomass until approximately Day 500. Coal and amendment are the primary substrates, which are converted 
to intermediate products by two types of bacteria. The intermediate products are then converted to methane. What is observed here is that on the one hand, the bacteria are growing along the column because coal is continuously available. The bacteria produce intermediate products from the bioavailable coal and amendment, and these products are then transported along the column. As soon as the available amendment vanishes, the intermediate products are produced no longer in sufficient amounts. The archaea are also establishing along the column and in the beginning, find reasonable amounts of intermediate products as their substrate. With less intermediate products being available along the column, the archaea slowly decay as their substrate becomes less and less available. As soon as the archaea are not well-established downstream of the intermediates-producing bacteria anymore, the methane generation in the column decreases. This is explained in more detail in Appendix B and Figures A1 and A2. With the bacteria still active, the coal is converted in the model, nevertheless.

Similar behavior can be observed for $\mathrm{DuMu}^{\mathrm{x}} \mathrm{Coal}^{++}$, except for a small patch of archaea that manages to attach and grow downstream of intermediates-producing archaea. Due to this, the archaea can grow up again, detach and attach further downstream to produce additional methane from Day 250 on.

The resulting methane production as well as the substrate consumption are now in line with the findings of Davis et al. [8]. The results show that cell attachment and biofilm detachment have significant effects on the model output. However, the model output still does not match the experimental data in every detail. With this case, we have shown that different processes interact in the model and while Hypothesis 1 alone was not able to explain the experimental findings, the combination of Hypotheses 1 and 2 leads to a model result that captures the key elements of the experimental study. This study provides a description of the possible processes without going into too much detail and without putting a focus on the fitting of many parameters that do not have experimental justification with the available data. Still, a basic approach of attachment and detachment for microbial cells was implemented using Equation (6) with a Rittman's exponent of “0.58" which obviously would deserve fitting in a future joint numerical and experimental study, where also the attachment and detachment processes related to MECBM production should be addressed in detail.

Concluding this part of the discussion, we note that the presented attachment and detachment equations and parameters should be handled with care. What we present is the first step that shows the direction for future modeling and experimental investigations.

Finally, let us briefly comment on adsorption. It is known that small amounts of the newly generated methane might adsorb to the coal and thus we should expect the model to slightly overestimate the methane produced from the column. The model can easily account for adsorption. Still, we refrained from doing so since we do not have reliable data to quantify adsorbed methane under the pressure conditions we have in the flow-through experiment.

\section{Conclusions}

Processes related to microbially enhanced coal-bed methane are extremely complex and strongly interacting. In this study, we introduce a numerical model that couples a previously validated batch-reaction system fully implicitly to a well-established flow and transport solver. This model was used to test various hypotheses on mechanisms that affect MECBM production in flow-through columns.

Two hypotheses were investigated by using four modeling cases implementing different assumptions regarding possible mechanisms. The results show that batch kinetics coupled to flow and transport in upflow column reactors might yield reasonable results for an initial time period; but this approach fails to match the experimental data in the long and indicates that further processes need to be considered in the coupling of MECBM reactions in flow through porous media.

In one case, we implemented inlet clogging, in another one retardation of amendment in the model. It is shown that methane production is prolonged and matches the experimental methane production results better than in the first case. However, a closer look at substrate consumption 
indicates drawbacks of this approach, mainly since a homogeneous biofilm distribution yields coal and amendment consumptions that are not in line with experimental findings from Davis et al. [8]. Therefore, Hypothesis 1 alone is not sufficient to explain the presented results.

The last approach in this study uses attachment and detachment of microbial cells and new biofilm growth combined with retardation effects for the amendment. In essence, this modeling case (Case 4) appears to be the most realistic of the four approaches evaluated here. The methane production matches the experimental results well and substrate consumption predictions are in line with experimental data from ${ }^{13} \mathrm{C}$ labeled studies. With this combination of Hypothesis 1 and Hypothesis 2, the experimental findings of Davis et al. [8] can be explained reasonably well, indicating that both amendment retardation and microbial cell attachment and detachment are relevant. We refrain from further "tuning" of parameters for this study. A scientific value beyond merely an expected better match to the experimental data can only be achieved with another joint experimental and numerical effort, which produces additional data.

To conclude further, we have shown that the numerical model can substantially aid in testing hypotheses and providing a basis for discussions; for example, specifically for this problem, the effects of attachment and detachment of cells, as well as amendment retardation, are of importance. The model allows us to analyze the complex interacting processes in detail. The discussion has demonstrated that there are a number of interesting effects which cannot be distinguished in sufficient detail in experiments, since even simple column experiments on processes of this complexity have a black-box character. Therefore, we suggest that further modeling can consider these processes and focus on the fine-tuning of the processes and parameters such as e.g., the Rittman's exponent, $\lambda_{\text {attach }}^{\kappa}$, and $\lambda_{\text {detach }}^{\varphi}$. Of course, this should be accompanied by further experimental evidence. The model, as it exists now, allows for the evaluation of the listed and possibly other parameters which subsequently might become the focus of future experimental work. We should note as well that not all the effects observed in the model need to be necessarily physically relevant phenomena. We advise here some care and, in particular, further work on cell attachment, biofilm detachment, cell re-attachment and re-growth, as well as amendment retardation could improve knowledge and predictions of MECBM production in unmineable coalbeds. More sophisticated modeling approaches regarding filtration and attachment-detachment processes are available and could be optimized to compare against new experimental column-scale results. The assumption that the biofilms are all fully active once the cells are attached can be discussed in the future, since a lag-phase or something similar with low production, in the beginning, is usually observed for biofilms.

Author Contributions: Conceptualization, H.C., R.G., and S.E.; methodology, H.C. and S.E.; software, S.E.; validation, S.E.; formal analysis, S.E.; investigation, S.E.; resources, K.D. and S.E.; data curation, S.E.; writing-original draft preparation, S.E.; writing-review and editing, H.C., K.D., and, R.G.; visualization, S.E.; supervision, H.C. and R.G.; project administration, H.C.; funding acquisition, H.C and R.G. All authors have read and agreed to the published version of the manuscript.

Funding: This research was funded by Deutsche Forschungsgemeinschaft (DFG, German Research Foundation) Project Number CL190-3 and we thank the DFG for supporting this work by funding SFB 1313, Project Number 327154368. Funding for this project was provided by the Department of Energy (DE-FE0024068). Partial financial support was provided by the Montana Research and Economic Development Initiative Contract \# 51040-MUSRI2015-05, NSF CHE-1230632, and Grant \# 1736255 (BuG ReMeDEE).

Conflicts of Interest: The authors declare no conflict of interest. The funders had no role in the design of the study; in the collection, analyses, or interpretation of data; in the writing of the manuscript, or in the decision to publish the results.

\section{Abbreviations}

The following abbreviations are used in this manuscript:

MECBM Microbially Enhanced Coal Bed Methane

REV Representative Elementary Volume 


\section{Appendix A. Modelling Parameters}

Table A1. List of used initial conditions, numerical, and physical parameters used in all simulations. Some parameters are given here again for completeness. Reaction parameters are presented and explained in Emmert et al. [14].

\begin{tabular}{|c|c|}
\hline Parameter & Value \\
\hline Newton MaxRelativeShift & $1 \times 10^{-8}$ \\
\hline Newton ResidualReduction & $1 \times 10^{-8}$ \\
\hline Newton MinSteps & 2 \\
\hline Newton MaxSteps & 18 \\
\hline Newton TargetSteps & 10 \\
\hline Newton RetryTimeStepReductionFactor & 0.5 \\
\hline Newton MaxTimeStepDivisions & 10 \\
\hline Linear Solver Reduction & $1 \times 10^{-7}$ \\
\hline MaxTimeStepSize & $21,600[s]$ \\
\hline Column height & $0.13858[\mathrm{~m}]$ \\
\hline Column diameter & $0.0525[\mathrm{~m}]$ \\
\hline Grid Cells & 80 \\
\hline Amendment (and Biofilm) injection period & $240[\mathrm{~s}]$ \\
\hline Water injection (flow rate) & $8.33 \times 10^{11}\left[\mathrm{~m}^{3} / \mathrm{s}\right]$ \\
\hline Decay rate coefficient Cases $1-3$ & $1 \times 10^{-3}\left[\mathrm{~d}^{-1}\right]$ \\
\hline Decay rate coefficient Case 4 & $1 \times 10^{-4}\left[\mathrm{~d}^{-1}\right]$ \\
\hline Amendment attachment coefficient Case $3 \lambda_{\text {attach, } \mathrm{C} 3}^{\mathrm{Am}}$ & $2.52 \times 10^{4}\left[\mathrm{~m}^{-1}\right]$ \\
\hline Amendment detachment coefficient Case $3 \lambda_{\text {detach, } \mathrm{C} 3}^{\mathrm{Am}}$ & $1.12 \times 10^{-4}\left[\mathrm{~s}^{-1}\right]$ \\
\hline Amendment attachment coefficient Case $4 \lambda_{\text {attach }, C 4}^{A m}$ & $5.14 \times 10^{4}\left[\mathrm{~m}^{-1}\right]$ \\
\hline Amendment detachment coefficient Case $4 \lambda_{\text {detach, } C 4}^{A m}$ & $4.96 \times 10^{-6}\left[\mathrm{~s}^{-1}\right]$ \\
\hline Cell attachment coefficient Case $4 \lambda_{\text {attach, }}^{\text {Bio } 4}$ & $7.51 \times 10^{5}\left[\mathrm{~m}^{-1}\right]$ \\
\hline Cell detachment coefficient Case $4 \lambda_{\text {detach } c 4}^{B i o}$ & $1.11 \times 10^{-8}\left[\mathrm{~s}^{-1}\right]$ \\
\hline Brooks Corey Lambda & 2 \\
\hline Brooks Corey entry pressure & $500[\mathrm{~Pa}]$ \\
\hline Irreducible Gas saturation & $1 \times 10^{-5}[-]$ \\
\hline Irreducible Liquid saturation & $1 \times 10^{-3}[-]$ \\
\hline Temperature & $298.15[\mathrm{~K}]$ \\
\hline Initial porosity & $0.48[-]$ \\
\hline Initial permeability & $2.23 \times 10^{-10}\left[\mathrm{~cm}^{-2}\right]$ \\
\hline Initial pressure (top) & $1.113 \times 10^{5}[\mathrm{~Pa}]$ \\
\hline Initial concentration of solutes & $0.0\left[\mathrm{~mol} / \mathrm{m}^{3}\right]$ \\
\hline Initial volume fraction archaea Case $1-3$ & $1 \times 10^{-7}[-]$ \\
\hline Initial volume fraction bacteria Case $1-3$ & $1 \times 10^{-6}[-]$ \\
\hline Initial volume fraction convertible coal & $4 \times 10^{-4}[-]$ \\
\hline
\end{tabular}

\section{Appendix B. Biofilm Evolution along the Column}

In modeling Case 4, explained in Section 3.4, the microbial cells are injected at the beginning of the simulation and can attach and detach along the column. Due to the presence of coal and the injection of amendment, the bacterial groups grow and detach further downstream. If coal or amendment are not present at a location in the column the biofilm decays. Therefore, the consumption of coal and the presence of amendment are essential for the bacteria. Archaea are dependent on the presence of the bacteria, as the bacteria convert coal and amendment to intermediate products, which are converted to methane by the archaea. Therefore, the archaea can only establish if bacteria produce intermediate products upstream of the archaea or at the same location.

Since the biofilm is not present homogeneously along the column anymore and intermediate products can not necessarily be converted where they are produced, attachment and detachment of microbial cells are essential for modeling Case 4 . In the following, we will present a snapshot of the biofilm distribution combined with the bioavailable fraction of coal on Day 185 and 365. 


\section{Appendix B.1. Results for 185 Days}

Figure A1 shows the distribution of bacteria and a bioavailable fraction of coal on the left and the distribution of archaea in the right plot (on the x-axis) on Day 185. The inlet region is at the bottom $\mathrm{y}$-axis, and the outlet on the top. In the left plot of Figure A1, the bioavailable fraction of coal (black) is consumed completely for the first $30 \%$ column height. The volume fraction of coal-consuming bacteria (green) is higher at the inlet region and decreases to almost 0 at $10 \%$ of the column height. From $15 \%$ to $35 \%$ of the column the volume fraction of coal bacteria is greater again. Amendment and coal bacteria (purple) show high volume fractions for the first $10 \%$ of the column, before they decrease and are not present anymore in significant numbers starting at approximately $20 \%$ of the column height.

Amendment- plus coal-utilizing bacteria establish themselves quickly due to amendment availability and consume most of the bioavailable coal out to approximately $10 \%$ of the column height before coal-only-consuming bacteria can establish themselves. Hence, a low volume fraction of coal bacteria is observed for this part of the column. With the available amendment being consumed within the first $10 \%$ of the column, the amendment- plus coal-consuming bacteria did not establish as well after that, and the coal-consuming bacteria volume fraction is able to increase from $15 \%$ to $35 \%$ of the column height. Bioavailable coal is consumed where there are bacteria, which can be seen at $35 \%$ of the column, where the increase in coal-consuming bacteria coincides with a decrease in a volume fraction of bioavailable coal.

$$
t=185 \text { days }
$$
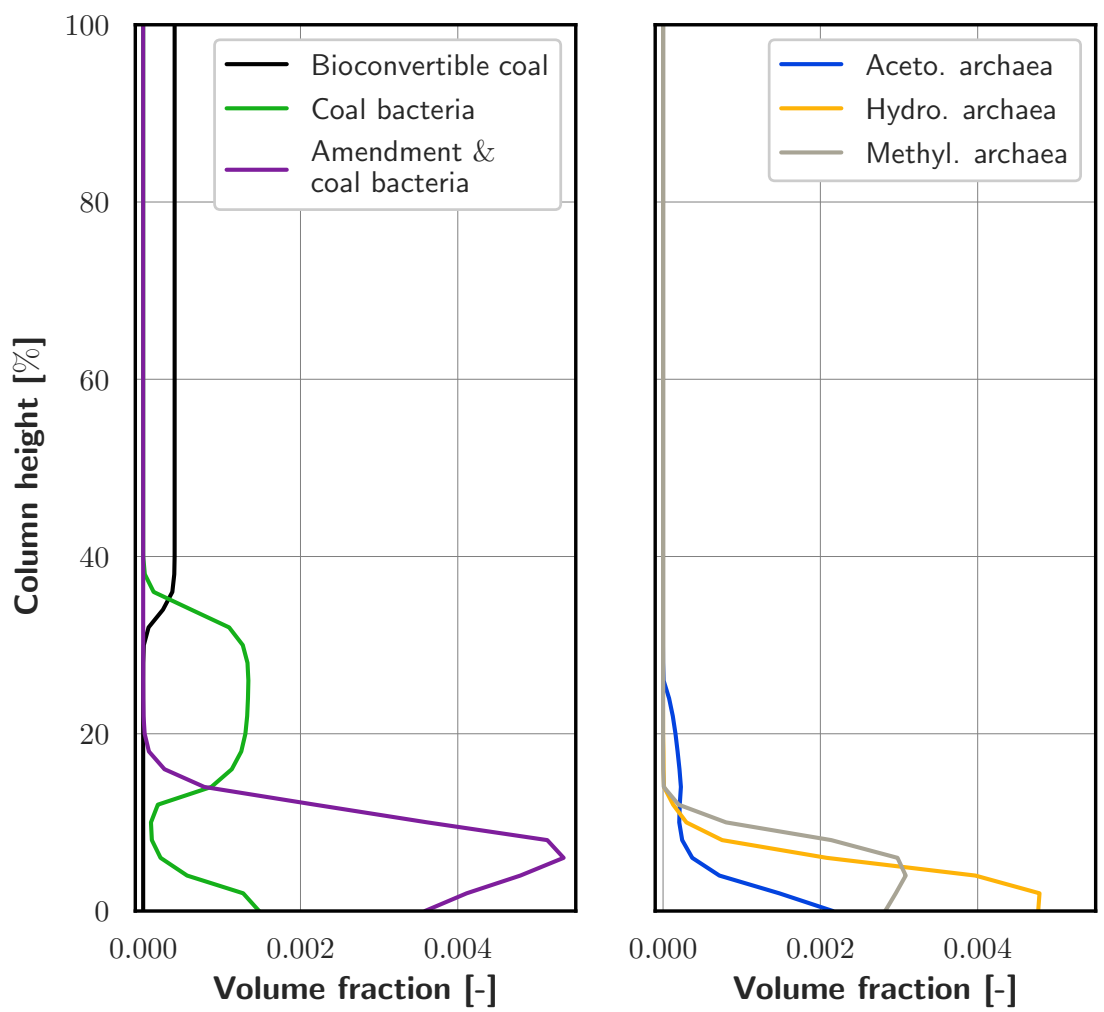

Figure A1. Distribution of microbial cells and bioavailable coal throughout the column (y-axis) on Day 185 as predicted for Case 4 . The (left) plot shows the volume fraction of two types of bacteria and bioavailable coal, while the (right) plot shows the volume fraction of three archaeal groups.

The right plot of Figure A1 shows the three types of archaea along the column. They all have their highest value at the inlet or within the first $5 \%$ of the column. As previously explained, they depend on the bacteria and it is visible, that they are only present where the bacteria are 
present, too. Methylotrophic archaea are assumed to only feed from amendment in Emmert et al. [14], and therefore depend on the amendment and coal-consuming bacteria. A similar peak that is observed for the amendment and coal-consuming bacteria is also visible for the methylotrophic archaea. The model predicts acetoclastic archaea to establish themselves further downstream than most other archaeal groups, since they consume the acetate produced by the coal-and amendment-consuming bacteria.

\section{Appendix B.2. Results for 365 Days}

Figure A2 shows the distribution of bacteria and a bioavailable fraction of coal on the left and the distribution of archaea in the right plot on Day 365. The inlet region is at the bottom of the $y$-axis, and the outlet on the top. In the left plot of Figure A2, the bioavailable fraction of coal is predicted to be consumed completely in the first $70 \%$ of the column. The volume fraction of coal bacteria in the first $30 \%$ of the column is similar to what was described for Day 185 in Figure A1 and remains at approximately the same level for the first $70 \%$ of the column. The model predicts the volume fraction of amendment- plus coal-consuming bacteria to peak within the first $20 \%$ of the column but to remain low for the remainder of the column.

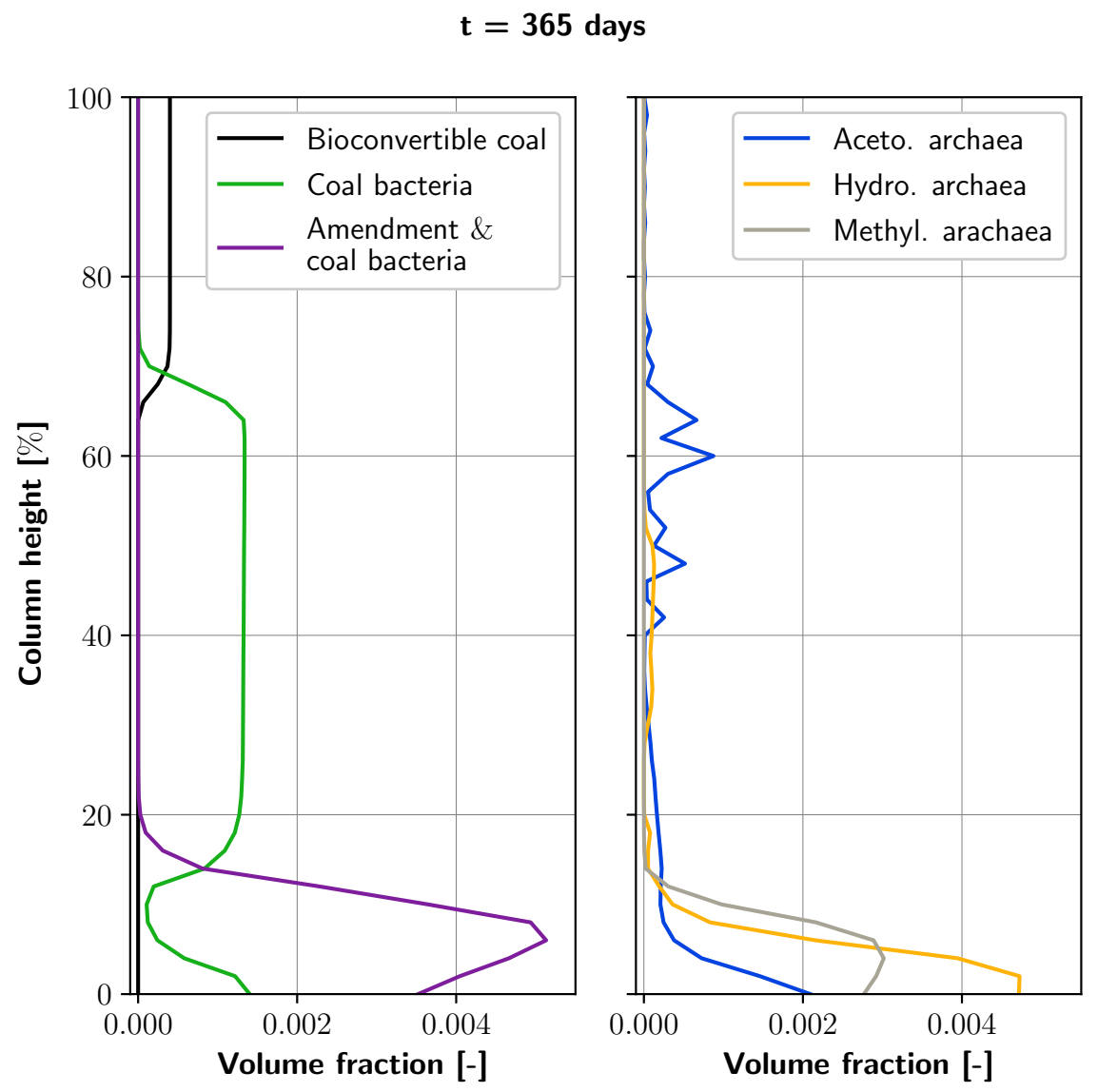

Figure A2. Distribution of microbial cells and bioavailable coal throughout the column on Day 365 as predicted for Case 4 . The (left) plot shows the volume fraction of two types of bacteria and bioavailable coal, while the (right) plot shows the volume fraction of three archaeal groups.

The right plot of Figure A2 shows the three types of archaea along the column. They all have their highest value within the first $10 \%$ of the column, and look similar to the distributions predicted in Appendix B.1 only with slightly lower values due to decay and detachment. For acetoclastic archaea, small increases in the volume fraction can be observed between $40 \%$ and $75 \%$ of the column height with a number of smaller peaks throughout the remainder of the column. These peaks are a physical 
process, however, it is numerically triggered. With attaching and detaching cells along the column, the numerical solver tolerance of $10^{-8}$ leads to minimal increases and decreases of volume fractions along the column. With more acetate being produced and transported downstream, the previously very limited number of microbial cells grow rapidly. We then observe a self-enhancing effect, as more biofilm is able to convert more of the acetate that passes along. This is only obvious for the fast-growing acetoclastic archaea in Figure A2, but also there are indeed smaller peaks for the hydrogenotrophic and methylotrophic archaea (this are not visible in Figure A2). Hydrogenotrophic archaea exhibit a second increase in volume fraction between $30 \%$ and $55 \%$ of the column height.

These increases in the volume fraction of the archaea can be attributed to the bacterial conversion of coal into intermediates (acetate and hydrogen), which support the growth of the archaea downstream of the bacteria. This indicates the importance of interactions between the different microbial species and why the attachment and detachment processes along the column are important.

\section{References}

1. Bruckner, T.; Bashmakov, I.A.; Mulugetta, Y.; Chum, H.; De la Vega Navarro, A.; Edmonds, J.; Faaij, A.; Fungtammasan, B.; Garg, A.; Hertwich, E.; et al. Energy systems Climate Change 2014: Mitigation of Climate Change. Contribution of Working Group III to the Fifth Assessment Report of the Intergovernmental Panel on Climate Change ed or Edenhofer; Cambridge University Press: Cambridge, UK; New York, NY, USA, 2014. Available online: https://www.ipcc.ch/pdf/assessment-report/ar5/wg3/ipcc_wg3_ar5_chapter7.pdf (accessed on 5 September 2020).

2. IEAI. World Energy Statistics and Balances; IEA: Paris, France, 2019.

3. Jones, E.J.; Voytek, M.A.; Corum, M.D.; Orem, W.H. Stimulation of methane generation from nonproductive coal by addition of nutrients or a microbial consortium. Appl. Environ. Microbiol. 2010, 76, 7013-7022. [CrossRef]

4. Barnhart, E.P.; Davis, K.J.; Varonka, M.; Orem, W.; Cunningham, A.B.; Ramsay, B.D.; Fields, M.W. Enhanced coal-dependent methanogenesis coupled with algal biofuels: Potential water recycle and carbon capture. Int. J. Coal Geol. 2017, 171, 69-75. [CrossRef]

5. Davis, K.J.; Barnhart, E.P.; Fields, M.W.; Gerlach, R. Biogenic Coal-to-Methane Conversion Efficiency Decreases after Repeated Organic Amendment. Energy Fuels 2018, 32, 2916-2925. [CrossRef]

6. Davis, K.J.; Gerlach, R. Transition of biogenic coal-to-methane conversion from the laboratory to the field: A review of important parameters and studies. Int. J. Coal Geol. 2018, 185, 33-43. [CrossRef]

7. Davis, K.J.; Lu, S.; Barnhart, E.P.; Parker, A.E.; Fields, M.W.; Gerlach, R. Type and amount of organic amendments affect enhanced biogenic methane production from coal and microbial community structure. Fuel 2018, 211, 600-608. [CrossRef]

8. Davis, K.J.; Platt, G.A.; Barnhart, E.P.; Hiebert, R.; Hyatt, R.; Fields, M.W.; Gerlach, R. Biogenic coal-to-methane conversion can be enhanced with small additions of algal amendment in field-relevant upflow column reactors. Fuel 2019, 256, 115905. [CrossRef]

9. Lupton, N.; Connell, L.D.; Heryanto, D.; Sander, R.; Camilleri, M.; Down, D.I.; Pan, Z. Enhancing biogenic methane generation in coalbed methane reservoirs-Core flooding experiments on coals at in-situ conditions. Int. J. Coal Geol. 2020, 219, 103377. [CrossRef]

10. Beckmann, S.; Luk, A.W.; Gutierrez-Zamora, M.L.; Chong, N.H.H.; Thomas, T.; Lee, M.; Manefield, M. Long-term succession in a coal seam microbiome during in situ biostimulation of coalbed-methane generation. ISME J. 2019, 13, 632-650. [CrossRef]

11. Senthamaraikkannan, G.; Gates, I.; Prasad, V. Development of a multiscale microbial kinetics coupled gas transport model for the simulation of biogenic coalbed methane production. Fuel 2016, 167, 188-198. [CrossRef]

12. Senthamaraikkannan, G.; Budwill, K.; Gates, I.; Mitra, S.; Prasad, V. Kinetic modeling of the biogenic production of coalbed methane. Energy Fuels 2016, 30, 871-883. [CrossRef]

13. Saurabh, S.; Harpalani, S. Modeling of microbial methane generation from coal and assessment of its impact on flow behavior. Fuel 2018, 216, 274-283. [CrossRef] 
14. Emmert, S.; Class, H.; Davis, K.J.; Gerlach, R. Importance of specific substrate utilization by microbes in microbially enhanced coal-bed methane production: A modelling study. Int. J. Coal Geol. 2020, 229, 103567. [CrossRef]

15. Jegatheesan, V.; Vigneswaran, S. Deep bed filtration: mathematical models and observations. Crit. Rev. Environ. Sci. Technol. 2005, 35, 515-569. [CrossRef]

16. Rockhold, M.L.; Yarwood, R.; Selker, J.S. Coupled microbial and transport processes in soils. Vadose Zone J. 2004, 3, 368-383. [CrossRef]

17. Molnar, I.L.; Johnson, W.P.; Gerhard, J.I.; Willson, C.S.; O'Carroll, D.M. Predicting colloid transport through saturated porous media: A critical review. Water Resour. Res. 2015, 51, 6804-6845. [CrossRef]

18. Bertsch, P.M.; Seaman, J.C. Characterization of complex mineral assemblages: Implications for contaminant transport and environmental remediation. Proc. Natl. Acad. Sci. USA 1999, 96, 3350-3357. [CrossRef]

19. Meckenstock, R.U.; Elsner, M.; Griebler, C.; Lueders, T.; Stumpp, C.; Aamand, J.; Agathos, S.N.; Albrechtsen, H.J.; Bastiaens, L.; Bjerg, P.L.; et al. Biodegradation: Updating the Concepts of Control for Microbial Cleanup in Contaminated Aquifers. Environ. Sci. Technol. 2015, 49, 7073-7081. [CrossRef]

20. Grösbacher, M.; Eckert, D.; Cirpka, O.A.; Griebler, C. Contaminant concentration versus flow velocity: drivers of biodegradation and microbial growth in groundwater model systems. Biodegradation 2018, 29, 211-232. [CrossRef]

21. Hommel, J.; Coltman, E.; Class, H. Porosity-permeability relations for evolving pore space: A review with a focus on (bio-)geochemically altered porous media. Transp. Porous Media 2018, 124, 589-629. [CrossRef]

22. Helmig, R. Multiphase Flow and Transport Processes in the Subsurface: A Contribution to the Modeling of Hydrosystems; Springer: Berlin/Heidelberg, Germany, 1997.

23. Brooks, R.H.; Corey, A.T. Hydraulic Properties of Porous Media; No. 3; Hydrology Papers Colorado State University: Fort Collins, CO, USA, 1964; pp. 1-27.

24. Koch, T.; Gläser, D.; Weishaupt, K.; Ackermann, S.; Beck, M.; Becker, B.; Burbulla, S.; Class, H.; Coltman, E.; Emmert, S.; et al. DuMux 3-An open-source simulator for solving flow and transport problems in porous media with a focus on model coupling. Comput. Math. Appl. 2020. [CrossRef]

25. Van der Vorst, H.A. Bi-CGSTAB: A fast and smoothly converging variant of Bi-CG for the solution of nonsymmetric linear systems. SIAM J. Sci. Stat. Comput. 1992, 13, 631-644. [CrossRef]

26. Sander, O.; Koch, T.; Schröder, N.; Flemisch, B. The Dune FoamGrid implementation for surface and network grids. Arch. Numer. Softw. 2017, 5, 217-244.

27. Iwasaki, T.; Slade, J.; Stanley, W.E. Some notes on sand filtration [with discussion]. J. Am. Water Works Assoc. 1937, 29, 1591-1602. [CrossRef]

28. Tien, C.; Turian, R.M.; Pendse, H. Simulation of the dynamic behavior of deep bed filters. AIChE J. 1979, 25, 385-395. [CrossRef]

29. Liu, X.; Civan, F. Formation damage and filter cake buildup in laboratory core tests: Modeling and model-assisted analysis. SPE Form. Eval. 1996, 11, 26-30. [CrossRef]

30. Rittman, B.E. The effect of shear stress on biofilm loss rate. Biotechnol. Bioeng. 1982, 24, 501-506. [CrossRef]

31. Speitel, G.E., Jr.; DiGiano, F.A. Biofilm shearing under dynamic conditions. J. Environ. Eng. 1987, 113, 464-475. [CrossRef]

32. Ebigbo, A.; Helmig, R.; Cunningham, A.B.; Class, H.; Gerlach, R. Modelling biofilm growth in the presence of carbon dioxide and water flow in the subsurface. Adv. Water Resour. 2010, 33, 762-781. [CrossRef]

33. Class, H.; Helmig, R.; Bastian, P. Numerical simulation of non-isothermal multiphase multicomponent processes in porous media: 1. An efficient solution technique. Adv. Water Resour. 2002, 25, 533-550. [CrossRef]

34. Class, H.; Ebigbo, A.; Helmig, R.; Dahle, H.K.; Nordbotten, J.M.; Celia, M.A.; Audigane, P.; Darcis, M.; Ennis-King, J.; Fan, Y.; et al. A benchmark study on problems related to $\mathrm{CO}_{2}$ storage in geologic formations. Comput. Geosci. 2009, 13, 409. [CrossRef]

35. Flemisch, B.; Darcis, M.; Erbertseder, K.; Faigle, B.; Lauser, A.; Mosthaf, K.; Müthing, S.; Nuske, P.; Tatomir, A.; Wolff, M.; et al. DuMux: DUNE for multi-\{phase, component, scale, physics,... $\}$ flow and transport in porous media. Adv. Water Resour. 2011, 34, 1102-1112. [CrossRef]

36. Flemisch, B.; Berre, I.; Boon, W.; Fumagalli, A.; Schwenck, N.; Scotti, A.; Stefansson, I.; Tatomir, A. Benchmarks for single-phase flow in fractured porous media. Adv. Water Resour. 2018, 111, 239-258. [CrossRef] 
37. Besemer, K.; Singer, G.; Limberger, R.; Chlup, A.K.; Hochedlinger, G.; Hödl, I.; Baranyi, C.; Battin, T.J. Biophysical controls on community succession in stream biofilms. Appl. Environ. Microbiol. 2007, 73, 4966-4974. [CrossRef]

38. Rochex, A.; Godon, J.J.; Bernet, N.; Escudié, R. Role of shear stress on composition, diversity and dynamics of biofilm bacterial communities. Water Res. 2008, 42, 4915-4922. [CrossRef] [PubMed]

39. Lyautey, E.; Jackson, C.R.; Cayrou, J.; Rols, J.L.; Garabétian, F. Bacterial community succession in natural river biofilm assemblages. Microb. Ecol. 2005, 50, 589-601. [CrossRef]

40. Kim, J.W.; Choi, H.; Pachepsky, Y.A. Biofilm morphology as related to the porous media clogging. Water Res. 2010, 44, 1193-1201. [CrossRef] [PubMed]

41. Fang, H.; Chen, Y.; Huang, L.; He, G. Analysis of biofilm bacterial communities under different shear stresses using size-fractionated sediment. Sci. Rep. 2017, 7, 1-14. [CrossRef] [PubMed]

Publisher's Note: MDPI stays neutral with regard to jurisdictional claims in published maps and institutional affiliations.

(C) 2020 by the authors. Licensee MDPI, Basel, Switzerland. This article is an open access article distributed under the terms and conditions of the Creative Commons Attribution (CC BY) license (http://creativecommons.org/licenses/by/4.0/). 